\title{
Hebreos y musulmanes durante la guerra civil en Melilla. Violencia politica y represión
}

\author{
María Elena Fernández Díaz \\ DOCTORANDO UNED MADRID
}

\section{Hebrew and muslims during the civil war in Melilla. Political violence and repression}

\begin{abstract}
RESUMEN:
El presente artículo constituye un intento de sistematización del fenómeno represor y concentracionario franquista en Melilla sobre las dos comunidades minoritarias de la ciudad en esos momentos, la hebrea

y la musulmana, sin desestimar en su contenido el contexto represivo y concentracionario general en dicha ciudad dentro de la dinámica represiva ejercida por militares y falangistas en España. El estudio de este proceso a escala local y sobre estas dos comunidades religiosas, con particularidades y consecuencias muy diferentes, a través de diferentes fuentes,

tanto orales como escritas además de archivos, nos permite observar las actuaciones que fueron los ejes sobre los que se movió la vida melillense de retaguardia durante la guerra civil teniendo una visión aproximada de la proyectada represión franquista llevada a

cabo en esta ciudad, dando lugar entre otras actuaciones al asesinato planificado y confinamiento en el campo de concentración de Zeluán de parte de la población melillense y protectorado cercano, incluyendo a miembros de estas dos comunidades.
\end{abstract}

\author{
PALABRAS CLAVE: \\ Melilla/Guerra Civil española/ \\ Levantamiento/Represión/Campo \\ concentración.
}

\begin{abstract}
:
This article attempts to systematize the concentration camp phenomenon Franco repressor and Melilla on the two minority communities in the city at that time, Jewish and Muslim, rejected in its content without the repressive context and overall concentration camp in the city within the dynamics of repression exercised by the military and Falangist Spain. The study of this process locally and on these two religious communities, with very different implications and consequences, through various sources, both oral and written files as well allows us to observe the actions that were the foundations on which moved rear Melilla life during the civil war have an approximate idea of the proposed Franco regime carried out in this city, among other actions leading to murder planned and confinement in concentration camp Zeluán of the population of Melilla and protectorate nearby, including members of these communities.
\end{abstract}


La investigación sobre la violencia política y la represión en la ciudad de Melilla es relativamente reciente y estudiada en determinados campos ${ }^{1}$. La dificultad para su estudio ha radicado en que algunos archivos y registros se han perdido, han sido destruidos o no han salido a la luz hasta el momento; pero con la nueva información localizada en diferentes publicaciones y archivos, junto con la aportación de testimonios, tanto de represaliados y de sus descendientes, como de observadores y actores directos, se puede cuantificar parte del alcance de la represión ejercida durante la guerra civil, sobre la población de Melilla y el protectorado próximo, incidiendo el presente estudio en las actuaciones sobre las comunidades hebrea y musulmana.

\section{LA PRIMAVERA MELILLENSE Y LOS INICIOS DE LA GUERRA}

Durante toda la etapa republicana las conspiraciones golpistas fueron continuas, aunque fue, tras el triunfo alcanzado por el Frente Popular en febrero de 1936, cuando algunos Generales en activo se reunieron en Madrid para discutir un posible golpe de Estado. El 19 de abril convinieron que fuera el General Mola junto con el General Galarza los que organizaran la conspiración, designando al General Yague como Jefe del movimiento insurreccional dentro del Protectorado, quien desde el primer momento se apoyará en la Falange de dicha zona para sacar adelante dicha conjura.

En Melilla las elecciones de febrero de 1936 supusieron el final de una intensa campaña electoral rodeada de mítines y en un clima intranquilidad sucediéndose diferentes episodios violentos silenciados a la prensa, siendo la efectividad de la propaganda frentepopulista la que movilizó mayoritariamente a gran parte de la población alcanzando un gran porcentaje de votos, frente a la desorganización de la candidatura de dentro-derecha. De 28.036 electores y 17.617 votantes, 12.761 lo hicieron al candidato del Frente Popular, Don Luis Barrena y Alonso de Ojeda y 4.830 a la derecha con su candidato Carlos Echeguren Ocio, votando en blanco o nulos 10.376, demostrándose que los afectos a la izquierda y a la Republica se contaban en esta ciudad a miles ${ }^{2}$, siendo tras este tramite repuestos los concejales destituidos en octubre de $1934^{3}$, saliendo elegido para presidir el Ayuntamiento Don Antonio Diez Martín, representante socialista y de la UGT melillense que sería asesinado en julio de 1936.

Durante la etapa republicana el movimiento obrero melillense, importado desde la península a fines del siglo XIX, logra su máxima expresión con el adveni-

\footnotetext{
1 Vicente Moga Romero esta a la cabeza de los historiadores locales. Ha realizado diferentes estudios y publicaciones donde el tema central es la represión. Las heridas de la Historia. Testimonios de la guerra civil en Melilla, Barcelona, Laboran Bellaterra, 2004 o Al Oriente de África, masonería, guerra civil y represión volumen I y II Melilla UNED 2005, donde el tema central es la represión a los masones melillenses y del protectorado oriental.

${ }^{2}$ ARQUES, E., 17 de julio La epopeya de África. Crónica de un testigo, Ceuta-Tetuán, 1938

${ }^{3}$ Ocho de estos concejales fueron fusilados por los sublevados.
} 
miento de esta y la instauración del su primer Ayuntamiento, participando activamente, tanto los sindicatos como los diferentes partidos, en su desarrollo social, económico y político.

Con el triunfo del Frente Popular se pone fin a un gobierno de derechas que había reprimido los movimientos obreros y políticos de la ciudad a la vez que se agudizan las tensiones sociales entre patronos, militares y obreros, que a veces superaban los simples choques dialécticos, ${ }^{4}$ siendo continuas las alteraciones de orden público como venia ocurriendo durante toda la etapa republicana, empeorándose esta situación a finales de la primavera.

Ante estos hechos, los militares se van uniendo a la secreta Unión Militar Española sintiéndose muy inclinados a las ideas fascistas de estos y de Falange, articulándose frente a una posible sublevación. Algunos fueron sorprendidos «in fraganti» al expresar abiertamente sus intransigentes opiniones, pasando a ser bajas de sus respectivos destinos, como el Tte. Ripoll de Ingenieros o del Tte. López de Haro de Regulares de Larache ${ }^{5}$.

Las medidas que adoptó la nueva autoridad civil y la militar frente a los diferentes altercados fueron la detención y enjuiciamiento de falangistas y de algunos alborotadores, además del cierre del Casino Militar que acabó siendo clausurado por el General Romerales, presionado por López Castillejos, Gaitán y Polonio Calvente, ${ }^{6}$ encrespándose aún más los ánimos entre ambas facciones, siendo este tipo de situaciones las que llevaron a la consecuente represión militar.

El 12 de julio, aprovechando las maniobras militares realizadas en el Llano Amarillo se ultiman los detalles del Levantamiento y serán captados los últimos militares de alta graduación de esta guarnición, siendo la sublevación en esta ciudad un adelantamiento impuesto debido a un chivatazo al Delegado del Gobierno, Jaime Fernández Gil de Terradillos.

Meses antes los sublevados habían confeccionado una lista informativa sobre los máximos responsables militares en las diferentes zonas de España, donde se les tachaba de adictos, dudosos o rojos, incluida la ciudad de Melilla y el Protectorado. ${ }^{7}$

${ }^{4}$ DIEZ MARTíN, P., Memorias de un anarcosindicalista en acción, Barcelona, Bellaterra. 2006. Hubo en esas fechas diferentes acontecimientos violentos dentro de la ciudad como el asalto a la sociedad militar «La Hípica» por parte de juventudes izquierdistas donde aparece en cabeza un hebreo; un atentado con disparos contra dos ciudadanos melillenses y una agresión al director de «La Vanguardia» (órgano de Acción Popular en la ciudad) Don José Sánchez Rueda además de desagravios hacia los militares del Casino Militar.

${ }^{5}$ Archivo Histórico Militar de Madrid. (AHMM) «Comunicaciones secretas cifradas desde el Protectorado y las ciudades de Ceuta y Melilla al Ministerio de Guerra». Colección África rollo 742 Febrero-julio 1936.

${ }^{6}$ GIL HONDUVILLA, J., Marruecos ;17 a las 17; Sevilla, Guadalturia, 2009. Estas personas pertenecían a la izquierda melillense, siendo todos ellos fusilados.

${ }^{7}$ Fundación Francisco Franco (F.F.F.) 623 s.f. 1939 Lista informativa de militares, adictos, dudosos y rojos. 
Las guarniciones del norte de África se unieron al Levantamiento, aunque con demostradas excepciones ya que hubo muchas detenciones y fusilamientos de militares en Ceuta, Melilla y Protectorado, ${ }^{8}$ como el Sargento de Ingenieros Pascual Sánchez Pujalte o el Capitán de Infantería Luis Casado Escudero, héroe de Igueriben. Sin embargo hubo algunos que disconformes no se adhirieron, siendo dados de baja pero librándose inexplicablemente del castigo y consecuente represión, ${ }^{9}$ seguramente amparándose en sus compañeros de armas que les prohijaron.

Si bien, se tiene como fecha de comienzo del Movimiento Nacional el 17 de julio en Melilla, la verdad es que se inició un día antes, el 16 a las $22 \mathrm{~h}$. en su cercano Protectorado, siendo el 3er Tabor del Grupo de Regulares de Alhucemas ํo 5 la primera unidad puesta en movimiento para iniciar la llamada Cruzada Nacional. ${ }^{10}$ Las siguientes fuerzas en movilizarse fueron las que salieron del cuartel de Segangan, los Regulares del 2 Tabor y 3er Escuadrón, que ocuparon las posiciones del aeródromo de Tauima y la Base de Hidroaviones del Atalayón.

En dicha Base, teniendo ya noticias de la sublevación, son recibidos a tiro de fusil y ametralladora encontrando una empeñada resistencia y resultando dicho escuadrón con dos muertos, si bien hubo bajas por las dos partes, siendo detenidos un capitán, varios suboficiales, tropa y paisanos que ofrecieron resistencia ${ }^{11}$, siendo este hecho el inicio de una sublevación fracasada que daría lugar a la guerra civil española.

A las 6 de la tarde, la Comandancia ya había sido tomada por los Regulares de Alhucemas. El General Romerales, máxima autoridad militar de la ciudad, se niega a entregar el mando y es detenido junto con algunos oficiales igualmente fieles a la legalidad republicana, por el Teniente Coronel del Estado Mayor Don Juan Seguí Almuzara, que ostentó en esos momentos la presidencia del Levantamiento, asumiendo el Coronel Solans el mando de la Comandancia, destituyendo y deteniendo a diferentes mandos sospechosos.

Cuando las tropas llegan a Melilla, se dedican a ocupar los edificios oficiales, cuarteles y la Central Eléctrica además de realizar patrullas de vigilancia, cacheo y detención en todos los barrios. ${ }^{12}$ Ese día por la noche, según propaganda divulgada por los sublevados, la ciudad estaba tomada. Esta información, repetida en

\footnotetext{
${ }^{8}$ Archivo General Militar de Guadalajara (AGMG) Campo de Concentración «La Alcazaba». Zeluán. Expedientes Procesales.

${ }_{9}^{9}$ Archivo Intermedio Militar de Melilla (AIMML), Expediente Regulares Europeos. Capitán Julio Fernández Benítez. Este se hizo cargo de la Mehal-la, ya que el Comandante Carlos Rubio López Guijarro no quiso adherirse al Movimiento iniciado, aunque inexplicablemente este fue ascendido años después a Teniente General y participó en el mando de la División Azul.

${ }^{10}$ ARRARÁS IBARREN, J., Historia de la Cruzada Española, Madrid, Ediciones Españolas S.A., 1940.

${ }^{11}$ AIMML Fondo Regulares Europeos. Exp. Coronel Eduardo Santana Franqui.

12 Ídem, Fondo Regulares Indígenas. Expedientes de los regulares del $2^{ }$Tabor y $3^{\text {er }}$ Escuadrón como Laiachi B. Mohamed nำ16.348 o Dahaman Ben Abdela Ben Al-Lal n 16.288.
} 
algunos manuales ${ }^{13}$, nos da una imagen falseada de lo sucedido ya que parte de la ciudadanía de Melilla salió a la calle durante al menos nueve días, intentando defender el orden republicano ${ }^{14}$.

El mismo 17 son detenidos en el Ayuntamiento el alcalde accidental y varios concejales que fueron posteriormente a parar al campo de concentración de Zeluán y a la cárcel militar de Rostrogordo, siendo algunos asesinados por su significación política.

Una vez tomada la ciudad por los sublevados, encuentran en algunos puntos resistencia ciudadana; algunos sindicalistas y afines a la izquierda declaran la huelga general e intentan armarse para repeler a las fuerzas sublevadas a la espera de una respuesta del gobierno central de Madrid, surtiéndose de armas asaltando las dos armerías existentes en la ciudad. En diferentes barrios, como Cabrerizas, se instalaron barricadas, tiroteando desde las azoteas a los falangistas y tropas sublevadas. Ni siquiera los militares de la Unión Militar Republicana Antifascista se atrevieron a utilizar la fuerza para defenderse, acabando los afectos a la Republica detenidos o huidos, tras unos pocos días de encuentros armados urbanos $^{15}$.

\section{LA REPRESIÓN EN MELILLA}

Comienza desde ese mismo momento una larga, dura y selectiva represión, producto de un programa estudiado con anterioridad, siendo en parte el reflejo de las instrucciones reservadas dadas por el General Emilio Mola Vidal, ${ }^{16} \mathrm{y}$ en parte, seguramente por los enfrentamientos surgidos durante toda la etapa republicana, sobre todo tras el triunfo del Frente Popular que hizo que muchos militares y falangistas actuaran vengativa e implacablemente ante ese envalentonamiento de las izquierdas.

El bando del General Franco fue leído en las calles de Melilla el mismo 17 por la tarde $^{17}$ e impreso en el diario «El Telegrama del Rif» al día siguiente. Allí estaba presente la justificación de la violencia política y la represión que se ejercerá sobre los

${ }^{13}$ Como en ARRARÁS IBARRÉN, J., Historia de la Cruzada Española, Madrid, Ediciones Españolas, 1940; FERNANDEZ DE CASTRO, R., El Alzamiento Nacional en Melilla. Hacia las Rutas de una nueva España, Melilla,1940; o LANUZA MEJIA, J., Así Comenzó... aportación a la historia de la sublevación militar de 1936 Ed. Andaribel México D.F. 1972

${ }^{14}$ AIMML Fondo Regulares Europeos. Expediente personal del Teniente General José Muslera González-Burgos que dejó escrito en su declaración jurada de julio de 1936 que los elementos de la antiEspaña se habían echado a la calle dispuestos a implantar la revolución social... manteniendo del día 18 al 25 tiroteos con núcleos de revoltosos.

${ }^{15}$ DIEZ MARTíN, P., Memorias de un anarcosindicalista en acción, Barcelona, Bellaterra. 2006

${ }^{16}$ Instrucciones reservadas de los días 24 y 30 junio 1936 en IBZ AZZUZ HAKIM, M., La actitud de los moros ante el Alzamiento, Málaga, Algazara, 1997.

${ }^{17}$ El teniente Bartomeu, con los Tenientes Latorre y Sánchez Suárez además de algunos falangistas fueron los encargados de recorrer las calles fijando el bando y declarando el estado de guerra. 
ciudadanos, siendo en principio la base jurídica sobre la que se realicen sus actuaciones falangistas y militares, unidas a las realizadas arbitrariamente por estos mismos.

Así mismo, el 20 de julio, el sublevado General Franco dirigió un despacho a todos los Generales de todas las Divisiones Orgánicas de España y los Comandantes Militares de Canarias y Baleares estableciendo nuevas consignas a seguir como la organización de Campos de concentración, donde debían ingresar los elementos perturbadores que serán empleados en trabajos públicos, siempre separados de la población, además de una disposición de apuntaba que para mantener el orden público se utilizaría la máxima energía fuese cual fuese el tipo de resistencia, incluida la pasiva. ${ }^{18}$ Con este estudio se ha comprobado que antes de ese despacho existía ya un Campo de Concentración en las inmediaciones de Melilla, el de Zeluán.

El impacto social de la guerra se unió en los primeros momentos a la nueva situación represiva que fue tanto física como administrativa, económica, religiosa, educativa y social, estando presente en los diferentes espacios de la vida ciudadana saldando en muchas ocasiones, posibles cuentas pendientes.

Para cuantificar los fallecidos acudimos a los inscritos en el Ayuntamiento, el registro civil y de los cementerios cristiano y hebreo de la ciudad de Melilla, siendo al menos trescientas trece personas, entre los que había civiles y militares, mujeres y hombres, cristianos, musulmanes y hebreos ${ }^{19}$.

Tabla 1: Fallecidos del 17 julio 1936 a febrero de 1940 inscritos en registros

\begin{tabular}{|c|c|c|}
\hline CRISTIANOS & MUSULMANES & HEBREOS \\
\hline 291 & 6 & 16 \\
\hline
\end{tabular}

Tabla realizada por la autora tras esta investigación

Como apunta el historiador Avilés Farré, se mataba para crear una sociedad nueva, purgada de elementos nocivos ${ }^{20}$, de esta manera se crea en Melilla un microcosmos con una renovada estructura social, donde nada se escapaba a la vigilancia de los sublevados, estando a partir de entonces todos los vecinos fichados e inscritos con sus antecedentes político-sociales tanto por Falange como por los militares.

Fue Melilla la primera muestra de la infraestructura represiva del Nuevo Estado donde se aprecia claramente la violencia política y la represión ejercida sobre la po-

\footnotetext{
${ }^{18}$ F.F.F.. Archivo. Consignas del General Franco 20 julio 1936.

${ }^{19}$ Hubo fusilados fuera de la ciudad, en poblados del protectorado oriental como Villa Sanjurjo o el zoco de Der Kebdani, además de desparecidos y fallecidos en el Campo de Concentración de Zeluán desconociendo hasta la fecha su número exacto por no estar inscritas dichas defunciones.

${ }^{20}$ AVILÉS FARRÉ, J., SUEIRO SEOANE, S., Y ELIZALDE, M.D., Historia Política, 1875-1939, Madrid, Ediciones Itsmo, 2002.
} 
blación, donde el principal objetivo fue la eliminación física de sus oponentes y la disuasión mediante la violencia de toda posible oposición, institucionalizándose una violencia selectiva; ${ }^{21}$ selectiva porque elegían a sus victimas, yendo a buscarlas a sus propios trabajos y domicilios para consumar en sus personas todo tipo de atropellos.

Los sublevados incluyeron en sus planes el exterminio y la persecución sistemática de la oposición política, observándose claramente en esta ciudad como en los primeros momentos la violencia política se materializó con la clausura de sindicatos y partidos de izquierda y la eliminación y detención de gran parte de las personas vinculadas a ese entorno ${ }^{22}$. Se llego al extremo de identificar a través de fotografías de mítines a varias personas para detenerlos y a recabar información a través de sus jefes para declararles no afectos a la nueva situación si habían participado de alguna forma en las protestas proletarias que atravesó Melilla durante la etapa republicana ${ }^{23}$.

Otra de estas medidas represivas fue la repatriación voluntaria y forzosa de miles de melillenses a la península, estando La Falange encargada declarando que «no se realizaban las repatriaciones para aliviar a la ciudad del problema obrero sino para depurar el ambiente moral y social de esta ciudad ${ }^{4}$ ».

Aparecen junto con los asesinatos, los fusilamientos y los juicios sumarísimos, las incautaciones de bienes, la censura de prensa, las depuraciones, los bautizos y confirmaciones en masa, los despidos, el hambre, el terror, el ostracismo social...y el confinamiento de todos aquellos que se les tenia por frentepopulistas o bien eran sospechosos de serlo. Fueron muchos ciudadanos confinados en las diferentes cárceles y el Campo de Concentración de Zeluán, siendo en los primeros momentos los falangistas los que participaron directamente en ejecuciones, palizas, registros, cacheos, purgas y otras tareas semejantes, disfrutando desde el primer día un local dentro de Comandancia General donde realizaban todo tipo de atropellos. ${ }^{25}$ Realizan estas actividades como contrapartida de esa persecución de que fueron objeto tras el triunfo del Frente Popular donde se consideró su agrupación ilegal, siendo todos perseguidos, llegando a pasar por la cárcel muchos de sus afilados y otros huidos al cercano protectorado.

El terror caliente se coló en los domicilios a través de la radio y la prensa, siendo el encargado el Teniente Coronel Darío Gazapo quien, aterrorizó a la población con violentísimas charlas desde EAJ-21 Radio Melilla, afirmando que los marxistas

21 FERNANDEZ DIAZ M. E., en el diario Melilla Hoy, «El 17 de julio y la multiculturalidad republicana: cristianos, hebreos y musulmanes represaliados», 19 de julio 2011.

22 Testimonio oral de A. Mansilla, hijo de represaliado. Se reunían los falangistas en el Parque Hernández en un banco y realizaban listas de sus victimas, quitando o poniendo a algunos a antojo.

${ }^{23}$ AGMG. Campo de Concentración «La Alcazaba». Zeluán. Expedientes Procesales.

${ }^{24}$ Archivo Central de Melilla (ACML) Fondo Repatriaciones, caja no 50 exp. Falange y las repatriaciones. Falange las gestionaba a través de su departamento de la Oficina local de Estadística y Colocación facilitando las propuestas de dichas repatriaciones.

${ }^{25}$ O NEILL, C., Una Mujer en la guerra de España Madrid, Turner 1979. 
y comunistas habían de desaparecer porque esa es la misión de la empresa iniciada añadiendo que el castigo sería ejemplar. ${ }^{26}$

De diferentes maneras el adoctrinamiento franquista hizo mella en la ciudadanía que se adaptó obligada a la nueva situación, quedando la política apartada en teoría, aunque hubo algunos que trabajaron en la clandestinidad intentando recuperar las libertades, incluso dentro del mismo ejercito. ${ }^{27}$

\section{VIOLENCIA POLITICA Y REPRESION CONTRA HEBREOS Y MUSULMANES EN MELILLA}

Estas dos comunidades instaladas desde hacia años en la ciudad, sufren de manera muy diferente la violencia política y la represión, siendo dos formas diferentes de mantener sobre estas comunidades el control.

Los hebreos, que se instalaron en ciudad a fines del XIX, participaban activamente en la vida política y cultural de la misma, siendo aquellos que pertenecieron a la izquierda castigados duramente, durante y después de la guerra civil, sufriendo una intensa violencia política y represión, solamente comparable a la sufrida por los cristianos sencillamente por pertenecer a ese grupo político, además de su adscripción religiosa y saneada economía, amparándose además en que algunos pertenecían a la masonería.

En cuanto a los musulmanes, solo poseían la condición de españoles unos cientos, aunque de hecho vivían en la ciudad en esos momentos más de tres mil, ${ }^{28}$ no siendo en general molestados puesto que, los más acaudalados e influyentes colaboraron con el Movimiento Nacional participando en todas aquellas actividades a que eran invitados como desfiles, actos oficiales, etc.; además de mediar a favor de los sublevados con las autoridades musulmanas administrativas y religiosas del Protectorado, no diferenciando en ocasiones quien era español y quien marroquí dentro de dicha comunidad.

Pero si nos fijamos en los musulmanes vecinos de las diferentes kábilas cercanas, estos serán los que se lleven la peor parte puesto que nutrirán las filas de Regulares yendo a luchar a primera línea de guerra siendo siempre carne de cañón; y los que no se alistaron se dedicaron al intercambio comercial a pequeña escala con la ciudad. El masivo alistamiento a las fuerzas regulares se debió en parte a la mala situación económica del Protectorado, sufriendo ese verano de

\footnotetext{
${ }^{26}$ MIAJA ISAAC, M. L., Sombras y Luces del Ayer Éxodo de Recuerdos, Morelia, México y charlas radiofónicas transcritas en El Telegrama del Rif durante los primeros meses de la Guerra Civil de Gazapo.

${ }^{27}$ En febrero de 1944, cuatro soldados colaboraban con los aliados proporcionándoles cobertura a través de una emisora local ilegal. Descubiertos, se enfrentan a las fuerzas de seguridad, falleciendo uno de ellos junto con el Inspector de Policía Torralba, siendo juzgados y fusilados los restantes el día 3 de agosto de 1994.

${ }^{28}$ SALAFRANCA J.F., Los judíos de Melilla, Málaga Algazara, 1995.
} 
1936 una gran hambruna, junto con la mala gestión de la República que fue en varias ocasiones advertida por los nacionalistas, ${ }^{29}$ siendo en muchas ocasiones tratados como inferiores.

Estos serán los que sufran las consecuencias represivas de los sublevados, que consistía, además de ser dirigidos hacia el reclutamiento, en una situación de hambruna tutelada y controlada por el nuevo Estado en connivencia con sus autoridades locales; dicha situación fue heredada de gobiernos anteriores, siempre debido a la mala gestión de los mismos, que no supieron atender suficientemente las necesidades del Protectorado, estando sus habitantes siempre sujetos a las ayudas españolas y a las inversiones extranjeras.

\subsection{LOS HEBREOS}

Entre el año 1931 y 1936 en Melilla vivían alrededor de los seis mil hebreos, integrados completamente en la sociedad melillense, siendo las actitudes antijudías casi de carácter anecdótico ${ }^{30}$.

La comunidad hebrea se fundó hacia 1883 y ya en 1893 existían varias escuelas-sinagogas, encontrando en 1907 seis escuelas hebraicas de forma oficial. Pero la Comunidad necesitaba un colegio propio donde recibieran sus hijos instrucción general y religiosa. Advirtiendo que la Administración de Melilla no les iba a solucionar el problema, en 1929 deciden recaudar dinero entre sus miembros y en la calle Duquesa de la Victoria, compran un terreno levantando un edificio de dos plantas, siendo el primer Colegio Hispano-Israelita en suelo español desde la expulsión en 1492. Dicha edificación fue incautada en 1936 y habilitada como Cuartel de las Milicias de Falange, siendo adaptada más tarde como sede del Gobierno Militar y devuelta por fin en $1945 .{ }^{31}$

De una forma u otra los hebreos que residían en Melilla fueron nacionalizándose muy lentamente acogiéndose a las diferentes normativas, ${ }^{32}$ aunque algunos no regularizaron su situación. Esta dejadez les benefició en 1936 ya que al no considerarles españoles no aparecían en la caja de reclutas absteniéndose de luchar en el bando sublevado, siendo incluso algunos expulsados del territorio español.

En cuanto a política, existen pocos datos sobre la actuación de los hebreos en los diferentes partidos ya que muchos registros han desaparecido. ${ }^{33}$ En febrero de 1936 una parte de dicha comunidad se hallaba vinculada a diferentes partidos polí-

29 IBZ AZZUZ HAKIM, M., La actitud de los moros ante el Alzamiento, Málaga, Algazara, 1997.

${ }^{30}$ LEVY, L., Algo más sobre judíos españoles: Melilla, en Revista Raices no 3-5

${ }^{31}$ SALAFRANCA J.F., Los judíos de Melilla, Málaga Algazara, 1995.

${ }^{32}$ R.D. 6-11-1916, R.D. 20-11-1924, R.D. 19-4-1931.

${ }^{33} \mathrm{La}$ información sobre este particular se ha obtenido del AIMML, el Telegrama del Rif, las diferentes actas del Ayuntamiento, testimonios orales de descendientes de represaliados y del registro del cementerio hebreo de Melilla. 
ticos de izquierda, siendo algunos de ellos militantes activos como Fortunato Mahfoda Serfaty († 19-07-1936) de las Juventudes socialistas o David Bitan (†19-071936) de Izquierda Republicana, siendo perseguidos y represaliados otros por su vinculación con la masonería como Alberto Benaim Benaim o Yudah Levy Ruas, ocurriendo algo muy parecido en todo el Protectorado.

Otra parte de los hebreos, minoritaria, se había vinculado a los partidos republicanos más conservadores en los que estaban integrados algunos personajes importantes de su comunidad como Isaac Benchimol Melul del Partido Radical y Abraham Benatar Taurel que fueron elegidos concejales del Ayuntamiento durante la II Republica o el rico comerciante Jacob Salama del partido progresí́ta conservador. Incluso sabemos de un hebreo falangista, Rafael Israel que cuando comenzó la guerra era ya «camisa vieja», aunque hubo de huir durante algunos meses al Protectorado cercano perseguido por sus correligionarios. ${ }^{34}$.

De 1936 a 1939, e incluso años antes ${ }^{35}$ y después, los sublevados se empeñaron en hablar de una conspiración judeo-masónica que quería destruir la cristiana patria española, propaganda que se verá en las diferentes editoriales de los diarios de Melilla y la península durante toda la guerra civil. La persecución a la comunidad hebrea aparece en varios estudios como más imaginaria que efectiva ${ }^{36}$, aunque esta fue practicada impunemente en esta ciudad, siendo algunos asesinados y los demás dirigidos, obligados y manipulados, obteniendo de ellos sus riquezas, propiedades y joyas.

En Melilla, si revisamos el Telegrama del Rif, encontramos referencias negativas hacia los hebreos, estando el mismo Franco convencido de que judíos, masones y comunistas formaban parte de la misma conspiración ${ }^{37}$, no ignorando que muchos eran favorables al bando republicano, aunque no llegó a introducir legislación antisemita, ni siquiera en la ciudad de Tánger, refugio de muchos hebreos ceutíes y melillenses tras el fallido Levantamiento.

La propaganda judeófoba de los sublevados tuvo consecuencias muy negativas para esta comunidad melillense, ya que comprobamos a través de testimonios y documentación que se les requisó las sinagogas, no pudiendo seguir a diario sus ritos religiosos y se ejerció sobre ellos una violencia política y una represión continuada en todos los ámbitos ${ }^{38}$.

\footnotetext{
34 Testimonio oral de Sr. Aquiba Benarroch, hijo del que fuera presidente a fecha 17 de julio de la Comunidad hebrea de Melilla, Don Yamin Benarroch.

${ }^{35}$ MOLA VIDAL, E., El pasado, Azaña y el porvenir. Las tragedias de nuestras instituciones militares, Madrid, Librería Bergua, 1934.

${ }^{36}$ LISBONA, J. A., El retorno a Sefarad, Madrid, 1993. o PEREZ J., Los judíos en España, Madrid, Marcial Pons, 2005.

37 PEREZ J., Los judíos en España, Madrid, Marcial Pons, 2005.

${ }^{38}$ Testimonios de Don Abraham Sultan, exiliado a Venezuela, que fue victima de la represión de los sublevados, siendo detenido y purgado con aceite ricino; y Don Aquiba Benarroch que cuenta como su padre ha de recoger los cadáveres de los hebreos asesinados y obligados a entregar todas las huchas los niños de su comunidad a las autoridades militares junto con otras muchas vejaciones.
} 
La represión religiosa y educativa les marcó hondamente, ya que la vinculación entre educación y culto religioso es para esta comunidad indisoluble, puesto que preparan a sus impúberes y jóvenes, tanto a nivel educativo como religioso, en su propio centro, reuniéndose allí a diario, siendo como se indica anteriormente, el gran colegio del Talmud Torah requisado en los primeros días por Falange, yendo a parar sus alumnos a otras escuelas donde no era posible hacerles un seguimiento académico-religioso, teniendo que realizar en sus casas reuniones religioso-educativas a espaldas de las nuevas autoridades.

De los ligados a la masonería, algunos fueron ejecutados, siendo todos sancionados y confiscados sus bienes, abonando multas con un tope de 50.000 pesetas, siendo renovadas constantemente con la intención de arruinarles, siendo otra de las medidas la prisión preventiva e ingreso en campos de concentración ${ }^{39}$, aplicando esta normativa sobre todos aquellos que sabían o intuían que habían ayudado al triunfo del Frente Popular.

La represión de tipo administrativo en Melilla, Ceuta y el resto del Protectorado fue igualmente intensa, pero si nos fijamos en la física, hemos de apuntar que en Melilla fallecieron muchos más hebreos que en el resto del territorio, quince en total, todos ellos varones; a su vez fueron enviados al Campo de Concentración de Zeluán, al menos, cincuenta y ocho, siendo algunos detenidos directamente por La Falange melillense.

Entre las victimas hebreas de la violencia de Falange y los militares, las más impactantes y crueles fueron las de los jóvenes Fortunato Mahfoda Serfaty, y Maimon Levy Levy. A Fortunato Mahfoda Serfaty, perteneciente a las juventudes socialistas consiguen asesinarlo el 19-7-1936 tras dos intentos. En el primero, lo sacan de su casa, lo acribillan a balazos y creyéndole muerto le abandonan. Enterados los falangistas de esta situación, volvieron a por él con una ambulancia, rematándole en la carretera de Alfonso XIII ${ }^{40}$.

A su vez el hebreo Maimon Levy Levy fue asesinado el 22-9-1936 a golpes tras ser torturado por los militares en el Batallón de Cazadores nํㅜ 3, falseando su acta de defunción apareciendo como fallecido a consecuencia de hemorragia cerebral. ${ }^{41}$

Varios hebreos afines al Frente Popular salen a la calle a defender el orden establecido falleciendo como consecuencia directa de la primera represión: siete

\footnotetext{
${ }^{39}$ La primera vez que aparece una ordenanza contra la Masonería en el Protectorado fue dada en Tetuán el 31 de mayo de 1937 en el Boletín Oficial de la Zona del Protectorado Español de Marruecos, dictada por el Alto Comisario Don Juan Beigbeder.

${ }^{40}$ LANUZA MEJIA, J., Así Comenzó...Aportación de la Historia de la sublevación militar de 1936, México, Andarivel, 1972.

${ }^{41}$ Don Aquiba Benarroch atestigua que su padre, Yamin Benarroch presidente de la Comunidad hebrea en esas fechas, fue el encargado de recoger el cadáver de este joven al que reconoció por haber trabajado para él en su fabrica de manufacturas, quedando muy impresionado ante el lamentable estado del cadáver, llegando a su casa muy afectado tras este hecho.
} 
en los primeros días, -entre el 19 y el 28 de julio- y más adelante cinco fusilados en el campo de Rostrogordo, además de otras dos víctimas de la represión: † 2209-1936 Maimón Levy Levy, fallecido en el Batallón de Cazadores no 3 y † 09-051938 Judas Millara Semani, fallecido en el hospital de la Cruz Roja a consecuencia de una herida recibida.

A su vez tenemos constancia de la muerte, tras finalizar la guerra civil, de otro, † 15-02-1940 Rubén Bitan, en la Prisión de partido de Melilla de tuberculosis pulmonar. Detenido y llevado el 9-9-1939 al campo de Concentración de Zeluán, fue filiado con el $\mathrm{n}^{\circ}$ 1307, siendo trasladado a dicha Prisión al ser clausurado como tal dicho Campo de Concentración ${ }^{42}$.

Sabemos además con seguridad que hubo un hebreo más ejecutado fuera de la ciudad, en el Protectorado español, se trata de Salomón Corcia Corcia, que residía en la yemaa de Tazaguin de la fracción de Izaomen de la kábila de Beni Said, que tras ser sometido a juicio sumarísimo no 712/1936 el 6 noviembre 1936, acusado de realizar manifestaciones tendenciosas contra al Movimiento Nacional y ocultación de víveres en su establecimiento comercial, fue condenado a pena de muerte siendo ejecutado en el zoco de Der Kebdani. Ignoramos hasta la fecha si hubo más victimas hebreas.

En los primeros días del Movimiento son detenidos, junto con otras personas, varios hebreos, ya que según los Regulares que los paran, estaban desocupados e infundían sospechas; uno de ellos, Fortunato Levy Levy, zapatero y vecino del Barrio Hebreo, fue detenido el 18 de julio e ingresado en el Campo de Concentración de Zeluán; su esposa escribió a las autoridades militares pidiendo su libertad. En abril de 1937 fue clasificado de primer grupo, es decir para ser puesto en libertad inmediata, ya que comprobaron que no tenía antecedentes de actividades socialistas o políticas ${ }^{43}$.

En agosto de 1936 al comprobar los sublevados que el Levantamiento no se hace efectivo y para sufragar los posibles y futuros gastos ocasionados por la guerra, el General Franco redacta personalmente un bando el vería la luz el 5 de agosto en Tetuán donde pedía el esfuerzo de todos los españoles para que se adhieran a estas suscripciones que surgen en torno del ejercito y donde pide a todos que aporten su sangre y su dinero. A resultas de estas donaciones se saturó el almacenamiento del Banco de España en Tetuán.

Para salvaguardar su integridad física y patrimonial, la población melillense también contribuyo con este y otros muchos llamamientos aportando parte de sus ahorros y de sus sueldos a "patrióticas y espontáneas" suscripciones que siempre aparecían publicadas en El Telegrama del Rif.

${ }^{42}$ Archivo del cementerio hebreo. Fallecidos de forma violenta, y AGMG. Campo de Concentración «La Alcazaba». Zeluán. Expedientes Procesales. Caja 2. Expediente 136. Ruben Bitan Aserraf.

${ }^{43}$ AGMG. Campo de Concentración «La Alcazaba». Zeluán. Expedientes Procesales. Caja 7. Expediente 575. Fortunato Levy Levy. 
A su vez se instaura el procedimiento de multar a todos aquellos desafectos al «Glorioso Movimiento Nacional» con una doble utilidad: represiva y económica. Según testimonios orales de miembros de la comunidad hebrea de Melilla, les hicieron firmar muchas de estas como si se tratase de voluntarias donaciones. ${ }^{44}$ Obligados y dirigidos, aportaron verdaderas fortunas, siendo en muchas ocasiones amenazadas sus familias. Como ejemplo esta imposición tenemos al Sr. Serfaty que hubo de donar a las fuerzas militares en el verano de 1936 su chalet de la caIle Alfonso XIII 45 .

Simultáneamente hubo muchas multas administrativas para aquellos que habían huido a Tánger, imponiéndoles elevadas sanciones como a Elías Jacob Danan y su hijo Elías Danan Levy, sancionados con 500.000 pesetas por su desafecto hacia el Glorioso Movimiento Nacional y negarse el hijo a cumplir el servicio militar como ciudadano español, o Moisés S. Beniflan Benzaquen, propietario de un comercio rebautizado tras su incautación «Nueva España» que huyó también a Tánger y que fue procesado por causa militar por sus actuaciones masónicas contrarias al Glorioso Movimiento Nacional y por la ayuda prestada a los centros revolucionarios marxistas.

Y muchos de los que siguieron residiendo en Melilla sufrieron del mismo modo estas sanciones como Jaime Levy, Jacob Lezra Garzón, Alberto Benarroch Benzaquen a los que impusieron una multa de 50.000 pts o a Moisés Salama Hassan de 10.000 pts que hubieron de ingresar en el Banco de España a disposición de la Comisaría de Multas, e incluso a los fallecidos se les sancionaba como a Mauricio Benhayon Benaim cuyos herederos hubieron de pagar mil pesetas ya que fue sancionado por el Tribunal de Responsabilidades Políticas de Melilla, sanción que apareció en el Boletín Oficial de Melilla № 449 de 30 diciembre 1939.

Aparece asimismo la llamada Comisión de Incautación de Bienes de Melilla que se dedicó a incautar y subastar los bienes de muchos hebreos entre los que se encontraban Moisés S. Beniflan Benzaquen, Moisés Benarroch Rolfe, Moisés Corcia Benain, José Mahfosa Serfaty, Abrahán Suiza Hassan y Moisés Salama Hassan $^{46}$.

Y si realizamos, a través del Telegrama del Rif, un computo de sus aportaciones en efectivo, de forma individual o como comunidad, podemos decir que sobrepasaron los dos millones y medio de pesetas, -de una sola vez aportaron en una suscripción a favor del ejercito 225.000 pesetas, una enorme cantidad comparada con lo que otros aportaban, que rondaba las cien pesetas ${ }^{47}$ - además apa-

44 Testimonios de la familia Serfati, SULTAN Y BENARROCH.

${ }^{45}$ AIMML Fondo Comandancia de Obras. Reparación Chalet Alfonso XIII.

${ }^{46}$ Diferentes Boletines Oficiales de la ciudad Autónoma de Melilla (BOME) publicados entre 1938 y 1942 y las sanciones publicadas entre noviembre y diciembre de 1937 en El Telegrama del Rif.

47 Según el testimonio oral de Aquiba Benarroch, los niños de la comunidad hebrea fueron obligados a entregar sus huchas a los sublevados; aunque a su vez afirma que a partir del 18 de julio la Sinagoga Yamin Benarroch (Or Zoruah) estuvo custodiada durante quince días por los legionarios gracias a la 
recen como los primeros que el 15 de agosto entregaron joyas para restaurar el encaje del Banco de España.

En contrapartida encontramos a. Jacobo J. Salama, representante de la Shell en esta ciudad que voluntariamente fue uno de los mayores colaboradores económicos de los sublevados, consiguiendo que los petroleros de la Shell, que se dirigían a España, lo hiciesen a puertos bajo control de los sublevados.

En todo el Protectorado se ejercía una estrecha vigilancia siendo todos observados por la policía secreta. Cualquier corrillo era objeto de sus sospechas aunque «a los israelitas se les dejaba en paz gracias a esta especie de contribuciones voluntarias a la causa»"

Sus riquezas fueron codiciadas por los sublevados siendo estas junto a sus filiaciones políticas izquierdistas y su religión los tres pilares sobre los que se gire la represión a esta comunidad.

Comprobando las nefastas consecuencias de la primera represión deciden mandar una comisión el día 18 de agosto poniéndose a disposición del recién creado Ayuntamiento, -de orientación claramente falangista -. Y a pesar de su constante colaboración, no les dejaron de molestar ejerciendo sobre ellos un riguroso control, distinguiéndose los sublevados por insultar a los ancianos, siendo clausuradas varias sinagogas además de realizar batidas nocturnas cuando en las azoteas de los edificios -donde estaban sus centros de culto-se recitaba la oración de Birkat Halebaná (bendición de la luna) lanzando sus reflectores sobre el grupo y deteniendo a los que lo formaban; incluso irrumpían en las horas de oración en las sinagogas deteniendo a los presentes, ordenándose además a los jefes de los cuerpos militares que privasen a los soldados hebreos de tener destino en dichos cuarteles recomendando una fuerte disciplina concentrándoles en Villa Jordana antes de su traslado al frente, siendo además privados los que poseían títulos superiores de acceder al curso de alférez profesional ${ }^{49}$ creándose el Archivo Judaico donde aparecían los nombres de los hebreos potencialmente peligrosos de las diferentes comunidades. A su vez la Falange se destacó por ridiculizar y mofarse de muchos de ellos dándoles a ingerir aceites de ricino y de avión usado teniendo de por vida consecuencias muy nefastas ${ }^{50}$.

Franco en persona, intuyendo que tanta presión ejercida daría resultados negativos, y ante las continuas proclamas antisemitas que daban otros generales, se dirigió al consejo de la Comunidad Israelita de Tetuán, comunicándoles que no

amistad que unía a Heli Rolando de Tella con el presidente de la Comunidad para que no fuese asaltada por los exaltados falangistas. Allí se dio refugio a varios hebreos enterados de los luctuosos acontecimientos.

${ }^{48}$ Fundación Anselmo Lorenzo (FAL) Grupos de África Sección Nacional de Coordinación. Servicio de Información exterior de fecha 11 noviembre 1938 Confederación Nacional de Trabajo de Barcelona.

${ }^{49}$ LEVY, L., Algo más sobre judíos españoles: Melilla, en Revista Raices nํㅜ 3-5

50 Testimonio de Don Abraham Sultan, que fue obligado a ingerir estos aceites y Don Aquiba Benarroch. 
prestaran demasiada atención a estas proclamas antisemitas del General Queipo de Llano en Sevilla. Todo esto para que las diferentes comunidades hebreas siguiesen colaborando libremente con la Causa Nacional51.

Debido al desarrollo de la guerra, en 1937 al Ayuntamiento de Melilla se le pedía información sobre la nacionalidad de los hebreos y musulmanes residentes para poder captarles en las filas franquistas como posibles soldados si eran realmente españoles ${ }^{52}$. La mayoría de los hebreos de Ceuta, Melilla y el Protectorado aparecen en las filas nacionales dentro de sus correspondientes reemplazos obligados a ir a la guerra, habiendo pertenecido muchos de ellos a diferentes asociaciones y sindicatos de izquierda como Moisés Cohen Edery, afiliado al sindicato de oficios varios afecto a la CNT, o Isaac Levy Levy que llegó a ser sargento del Tercio en la Campaña de Liberación ${ }^{53}$. Asimismo aquellos hebreos que estaban en el Campo de Concentración de Zeluán y les llegaba la hora de incorporarse a filas, se les liberaba y mandaba siempre a primera línea del frente, si se comprobaba su nacionalidad española.

Pese a toda la propaganda antijudía franquista que apareció en los diferentes diarios y la represión consecuente ejercida sobre ellos, en Melilla esta comunidad logró sacudirse esa hostilidad y estar integrada de nuevo al completo, exiliándose voluntariamente y con posterioridad algunos de sus miembros, que se dirigieron a Sudamérica y más tarde a Israel tras la creación de este nuevo Estado.

En 1945 se les devuelve el Colegio Hebreo siendo en la actualidad una de las comunidades que colaboran más activamente en la vida política, estando varios de sus miembros integrados dentro del actual Ayuntamiento, además de en partidos políticos, tanto de izquierda como de derecha.

\subsection{LOS MUSULMANES}

No solo cristianos y hebreos sufrieron las consecuencias represivas del nuevo Estado, los musulmanes también la sufrieron aunque hay que apuntar que de diferente forma, pues eran muy necesarios para el desarrollo de la guerra. Muchos aparecen como fuerzas de primera línea y los de la retaguardia hubieron de realizar labores a favor del Movimiento Nacional como delaciones y espionaje o simplemente favoreciendo libremente a la causa con su apoyo incondicional, como varios musulmanes notables españoles de Melilla y algunos de los alrededores que

51 LISBONA, J. A., El retorno a Sefarad, Madrid, 1993.

52 ACML Fondo Central Asuntos Exp. 530. Documento donde pide información la Comisaría de Guerra de Melilla sobre los extranjeros, hebreos y musulmanes sobre su situación de ciudadanía para enrolarles en el ejército franquista.

${ }^{53}$ AGMG. Campo de Concentración «La Alcazaba». Zeluán . Expedientes Procesales. Caja 7. Expediente 576. Isaac Levy Levy. 
trabajaban directamente con el ejercito, como el Sr. Ahmed Amor Zrak o el mismísimo hermano del General Mizzian.

Musulmanes que vivían en Melilla y tenían la condición de españoles, eran tan solo unos cientos, -aunque vivían muchísimos más sin esta condición, alrededor de tres mil- siendo los más acomodados mínimamente molestados, dedicándose a apoyar activamente al Levantamiento, tratando y comerciando con los militares, siendo durante la guerra civil por este motivo agasajados y recompensados por tal adhesión.

El posicionamiento que tomaron los jefes marroquíes de las diferentas zonas del Protectorado fue la clave para el triunfo y posterior desarrollo de la contienda, siendo muchos de estos pensionados de por vida.

Muchos de los que serán reclutados lo hicieron por pasar por acuciantes necesidades económicas, ya que ese año el campo del protectorado transitaba por una gran hambruna debida a las malas cosechas, dotándoles en su alistamiento de una importante la soldada. Otros se alistaron por vivir experiencias nuevas, salir de su tierra, pasar a España y vivir de otra forma, siendo otros más inteligentes engañando a las autoridades melillenses haciéndose pasar por españoles obteniendo cartillas de racionamiento, sin necesidad de alistarse ${ }^{54}$. A esta situación se uniría la mala gestión de la Republica, que aunque advertida por los nacionalistas y por el primer Diputado por Melilla, Don Antonio Carballar Acuña ${ }^{55}$, no se hizo nada por remediarla.

Los primeros alistamientos para esta campaña en las Fuerzas de Regulares en la zona de Melilla datan del día 23 de julio de $1936^{56}$. La función de estos regulares dentro del ejercito español era el de ahorrar sangre nacional cuando se hiciera preciso usar las armas, como era el caso.

Las consignas de los sublevados, en líneas generales, en cuanto a la población musulmana, fue la de mantenerles unidos en contra de la Republica a través de una intensa propaganda donde se le hacia creer que era una yihad contra de los sin Dios, ejecutando alianzas con los diferente kaides y bajaes que debían sus cargos a los militares por haber luchado a su lado en las diferentes guerras de Marruecos. Se atrajeron de esta forma a los dirigentes musulmanes para que no hubiese opción de un intento de autonomía hacia España, ya que existía en el Protectorado un núcleo claramente nacionalista que reivindicaba desde hacía tiempo la independencia, manifestando su repulsa por los alistamientos ${ }^{57}$.

\footnotetext{
${ }^{54}$ El documental de Driss Deiback Los Perdedores estrenada en 2009 contiene testimonios de varios musulmanes de las fuerzas Regulares que participaron en la Guerra Civil y que aún están vivos.

55 IBZ AZZUZ HAKIM, M., La actitud de los moros ante el Alzamiento, Málaga, Algazara, 1997. El Diputado Sr Acuña defendió en más de una veintena de debates parlamentarios en el Congreso de los Diputados, los intereses de los musulmanes.

${ }^{56}$ AIMML Revisados miles de expedientes dentro del Fondo de Regulares Indígenas. Los reclutados en la zona oriental y del Rif a fecha 8 de agosto de 1936 eran de 3873 hombres según las estadísticas publicadas por IBZ AZZUZ HAKIM, M., La actitud de los moros ante el Alzamiento, Málaga, Algazara, 1997, donde en la zona de Melilla aparecen alistados el 75,02\% frente al 24,08\% en la zona occidental.

57 IBZ AZZUZ HAKIM, M., La actitud de los moros ante el Alzamiento, Málaga, Algazara, 1997.
} 
La labor de España en Marruecos fue realizada de manera muy personal a través de las Intervenciones Militares y los encargados directos de organizar los alistamientos fueron sus Interventores. Estos durante toda la guerra sirvieron de enlace entre las fuerzas militares españolas y los marroquíes, consiguiendo que se siguieran alistando, aun con reticencias, miles de ellos, invirtiendo muchísimo dinero en una activa propaganda para el reclutamiento.

En la zona oriental (Melilla-Rif) se encontraba encargado de las mismas el Interventor, Coronel Bermejo, que con una veintena de años de servicio en Marruecos, alternaba diferentes actividades con la labor política de sumisión de las kábilas. Gran conocedor de las kábilas del Rif, fue uno de los puntales más firmes de los sublevados en Marruecos y su puesto de primera línea de la Intervención Regional fue inigualable, ya que, tenía gran ascendiente cerca de los jefes de las diferentes kábilas, como S. E. Abd Del Kader, Amar Uchen, kaides y demás prestigiosos musulmanes que ejercían autoridad, así como en los demás habitantes de la región. El General Franco le tuvo como uno de los pilares fundamentales de la victoria ya que además de todo esto fue el encargado de no dejar pasar propaganda republicana para soliviantar a los kabileños. ${ }^{58}$

Ante esta situación continuada de apoyo de las autoridades marroquíes a los sublevados, la Republica intentó diferentes acercamientos hacia estas, que se materializaron en algunos estudios a primeros de 1938 para conocer las posibilidades de una posible subversión en el Marruecos español ${ }^{59}$.

Las primeras víctimas de la Guerra Civil, pertenecientes al bando nacional y de religión musulmana, fueron dos áscaris de regulares que el mismo día 17, tras atacar la base de Hidroaviones del Atalayón, caen muertos: el sargento indígena Lahasen Ben Mohamed y el soldado moro Mohamed Ben Mohamed Ben Ahmed $^{60}$. Otro musulmán perteneciente a Regulares cae muerto a su vez en el edificio de la Comisión de Limites de Melilla. A estas muertes les seguirán miles de fallecidos en los diferentes enfrentamientos en la península con las fuerzas leales a la Republica.

En cuanto a los fallecidos musulmanes en Melilla a consecuencia directa de la represión física iniciada por los sublevados, podemos decir que tenemos constancia hasta el momento de al menos seis en los inicios de la guerra civil: un varón, «un moro, dueño de un cafetín de unos veintidós años»61; Salah Ben Useauy, sol-

${ }^{58}$ El Telegrama del Rif, 24 de marzo 1940 Homenaje Al Coronel Bermejo.

59 Fundación Anselmo Lorenzo. (FAL) Fondo sobre Marruecos-SECRETO-Memoria acerca de las posibilidades de sublevar en contra de los facciosos las kábilas del sur marroquí y el Sahara españoles. Barcelona febrero 1938.

60 GIL DE HONDUVILLA, J., Marruecos ;17 a las 17; Sevilla Guadalturia 2009

${ }^{61}$ ACML Leg. I Guerra Civil Algunos documentos relacionados con el Glorioso Movimiento Militar iniciado el 17 de julio, extraídos de las carpetas de correspondencia entregadas en el Archivo el 20 de octubre de 1938 recogido por Vicente Moga Romero en Las heridas de la Historia. Testimonios de la guerra civil en Melilla, Barcelona, Laboran Bellaterra, 2004. 
dado de Regulares no 5 y otros tres civiles, Sal-lam Ben Aled Er Ramadam, Fatma Ben Amar Ben Mohatar y Fatma Ben Hammu Hedi62.

Sal-lam Ben Aled Er Ramadam aparece fallecido el 19 de Julio de 1936 por herida de arma de fuego pero inscrito el 15 de octubre de 1938 en el registro civil recibiendo sepultura en el Sidi Guariach-cementerio musulmán cercano a la ciudad ${ }^{63}$. El inscribir el fallecimiento de una persona después de dos años de su muerte es muy extraño. En el registro civil de Melilla, entre los años 1936 a 1941, solo se encuentran tres casos: los tres son musulmanes fallecidos en los primeros momentos del Levantamiento, ignorando hasta el momento el porque de dicha inscripción con tanto retraso.

Hubo en Melilla solo cuatro mujeres fallecidas de forma violenta relacionadas con la represión, dos cristianas y dos musulmanas, estas dos últimas aparecen inscritas en el registro civil el treinta y uno de enero de 1938, pero señalándose como fallecidas el 26 de julio de 1936. Eran Fatma Ben Amar Ben Mohatar de Tensamán y Fatma Ben Hammu Hedi de Beni-Sicar, ambas domiciliadas en la calle Estopiñán no 15, anotando que su profesión era el de prostitutas. Fueron, según consta en el registro civil, hallados sus cadáveres el 29 de julio de 1936 en las proximidades de los Polvorines Nuevos de Horcas Coloradas y se apunta que debieron hallar la muerte tres días antes, es decir el día 26 de julio de 1936 practicándose la inscripción por orden de la Superioridad. Aparecen ambas años después en un Boletín Oficial de Melilla como fallecidas a causa de los bombardeos que el 26 de julio de 1936 sufrió la ciudad, aunque al mismo tiempo tenemos información por testimonios orales y escritos de la violencia con que se conducían los falangistas aprovechándose de su situación de poder, para abusar de mujeres, sobre todo de las que se dedicaban a la prostitución ${ }^{64}$.

En el Boletín Oficial de Melilla no 458 de fecha 15 mayo de 1940 encontramos a otro musulmán fallecido, Ibraim Ben Soliman, miliciano voluntario del vapor Nuria $R$, pero hasta el momento ignoramos las circunstancias exactas de su deceso, lo que si sabemos es que hubo tripulantes de ese buque republicano en el Campo de Concentración de Zeluán.

Para agradecer y favorecer a los musulmanes españoles su colaboración, el día 23 de noviembre de 1937 aparecen las ordenanzas dadas por el Exmo. Señor Gobernador General de las Plazas de Soberanía, y se crean en las Plazas de Ceu-

\footnotetext{
62 Nueva información localizada tras una exhaustiva investigación en el Archivo Civil de Melilla, donde se revisaron todos los libros de inscripciones de defunción del 17 de julio de 1936 hasta enero de 1942. No podemos descartar que existan algunos más, ya que al no poseer en esos momentos cementerio musulmán Melilla, si hubo más, fueron enterrados en cementerios de fuera como en el de Sidi Guariah o Nador.

${ }^{63}$ No es obviamente la misma persona que aparece en el legajo del Ayuntamiento, porque este musulmán en el momento de fallecer tenía cuarenta y nueve años y no veintidós.

${ }^{64}$ En escritos de Carlota O Neill o el testimonio del Sr Gallego en el Archivo de la Experiencia.
} 
ta y Melilla "Las Comunidades de musulmanes de nacionalizados españoles para salvaguardar su religión, usos, costumbres e instituciones sociales».

Dichas Comunidades fueron creadas en unos tiempos donde las circunstancias políticas lo exigían, debido a la guerra y con fines puramente gubernativos, pero para que siempre marcharan de acuerdo con las Autoridades de dichas Plazas, siempre dando sensación de que no estaban controladas por el Servicio de Intervenciones. En Melilla el domicilio oficial estaba en la calle O Donell no 11 denominándose "Casa de la Comunidad Musulmana» en el cual ondearían las banderas española y la Verde del Imán.

En esta primera Comunidad creada en Melilla fue elegido presidente honorario el General Mizzian; presidente, su suegro Ahmed Amor Zrak; vicepresidente Sid Admed Mizzian Mohamed Bel-Kasem, (hermano de General Mizzian que fue al poco destituido por borrachín), junto a 11 vocales, de los cuales solo cuatro eran españoles, además de un secretario y un conserje, también españoles, especificando en la elección de todos ellos, que tanto Mizzian como su hermano no eran españoles sino marroquíes de Mazuza, Beni-Enzar. La elección de miembros marroquíes en diferentes épocas generó múltiples discusiones y malestar entre los nacionalizados ya que todos se disputaban el poder para poder trampear con los caudales y mercancía entregada por España a dicha Comunidad.

De esta Comunidad Musulmana de Melilla decían los musulmanes melillenses que su única preocupación era cobrar las subvenciones de España, denominándola «como-nada» dando a entender la inutilidad de dicho centro; además existieron por su intolerancia múltiples enfrentamientos ${ }^{65}$.

Las penurias de la guerra y el haber pasado por diferentes experiencias hacen que muchos soldados musulmanes regulares abandonen a sus compañeros de armas y se trasladen desde la península a Marruecos, siempre sin autorización, siendo declarados desertores; a algunos de estos los logran detener yendo a parar al Campo de Concentración de Zeluán.

Además de cristianos y hebreos hubo musulmanes que aparecen en las listas de la Comisión de Incautación de bienes de Melilla como Mohamed Ben Amichial e lbraim Ben Soliman, junto con algunos a los que se les abre incoación de expedientes de responsabilidades políticas como Tahar Ben Buchat Mohamed, Ben Aixa Ben Amar, soldado de Regulares oㅜ 13.361- condenado a la multa de quinientas pesetas como sanción económica-, Mohamed Ben Amor Mohatar, Mensor Ben Moh Haddu (Mehala no 2), Ibrahim Ben Soliman, Al Lal Bali (soldado) o Mohamed Ben Amar (soldado).

${ }^{65}$ AIMML Fondo Comandancia General Caja I, Sobre 1, exp. 2 y 4., 20 diciembre 1937. En una discusión, en diciembre de 1937, llegaron a las manos Hamed Amor y Hamed Mezzian por, inscribir o no en el registro civil de Melilla los casamientos entre musulmanes, teniendo que intervenir en el apaciguamiento de ánimos el Sidi Mohamed Temamani, jefe nacionalista para arreglar el asunto, obedeciendo órdenes del Alto Comisario. 
Sobre la población musulmana, en esos momentos, la más pobre, se materializa una represión por el hambre, dependiendo siempre de la generosidad de las autoridades españolas y marroquíes, pasando por una situación límite tras la Guerra Civil donde en el Protectorado español sufrió una situación tan precaria que aparecían incluso fallecidos por inanición, sobre todo menores, situación que dio lugar a un grave problema, ya que fueron muchos musulmanes, familias enteras, las que ante la situación angustiosa que atravesaban huyeron a escondidas a la vecina zona francesa, dándose el caso de fallecer algunos ahogados al intentar pasar el río Muluya.

Al mismo tiempo a Melilla llegaban infinidad de musulmanes que recorrían los establecimientos registrando las basuras e ingiriendo desperdicios para aplacar el hambre constituyendo un grave problema ciudadano; sin embargo se veía como los kaides y pensionados por España disfrutaban de bienestar e ingresos ya que se quedaban con parte de lo que les llegaba de la ayuda española, siendo los responsables de un reparto -que no realizaban en su totalidad-, situación denunciada en varias ocasiones y que no remediaron las autoridades españolas en ningún momento aún teniendo conocimiento de dichas anormalidades. Un claro ejemplo de esto concurrió en Farhana donde una denuncia realizada por diferentes personas al Chej Tahar Ben Haddu Ben Hamar quedó sin resolución por lo que mandaron un informe al Capitán Manuel Chacón que en esos momentos ostentaba el cargo de Capitán Interventor del Guelaya ${ }^{66}$.

Por otro lado gran parte de los musulmanes marroquíes soñaba ante esta tesitura con la vuelta de Abd El Krim que les librara del hambre y del extranjero cristiano ya que la falta de víveres y bienestar fue empobreciendo, si cabe, aún más a los habitantes de nuestro protectorado, liberación que llegó años después con el fin del mismo, aunque no les sacó de esta situación de pobreza, sobre todos a los habitantes del Rif.

\section{HEBREOS Y MUSULMANES EN EL CAMPO DE CONCENTRACIÓN DE ZELUÁN}

En el Campo de Concentración de Zeluán fueron ingresados más de un millar y medio de personas a lo largo de los meses que duró la Guerra Civil y entre ellos hasta el momento encontramos al menos catorce musulmanes y cincuenta y ocho hebreos, aunque por muy diferentes razones.

Javier Rodrigo Sánchez data los primeros campos de concentración en noviembre de $1936^{67}$, pero el Campo de Concentración de Zeluán fue el primero, pri-

\footnotetext{
66 Ídem Fondo Comandancia General. Caja II, sobre 6 exp. 55

${ }^{67}$ RODRIGO SANCHEZ, J., Internamiento y trabajo forzoso: los campos de concentración de Franco en Hispania Nova nº 6, 2006.
} 
mero en España y en Europa ya que data del día siguiente del Levantamiento en Melilla.

Javier Lanuza Mejia fija su inicio en la misma noche del día 17 de julio: «y entre los españoles presos que llevaron los de Falange a Zeluán, a partir de la noche del 17.... „68 Pero en El Telegrama del Rif aparece como fecha de su inicio un día después, el 18; de lo que se puede deducir que se abre en las horas posteriores al Levantamiento y unido a este, muy posiblemente en la misma madrugada del 18 de julio, existiendo con toda seguridad como tal el 19 de julio ya que ese mismo día ingresan varios ciudadanos entre los que se encuentra el hebreo Santos Levy Murciano69.

El ingreso de hebreos en el campo de concentración de Zeluán fue una de las medidas represivas utilizadas por los sublevados ya que muchos habían participado activamente en el triunfo del Frente Popular estando afiliados a sindicatos y partidos; el de los musulmanes por desertores dentro de las unidades de Regulares, alguno acusado de sedición y otros por delitos comunes.

En cuanto a los musulmanes, sabemos que ingresaron por el momento catorce, de los cuales solo dos por ir en contra del Movimiento Nacional, uno por intentar pasar a la Península sin permiso y el resto por desertores. Esto no quiere decir que en futuras investigaciones aparezcan nuevos datos que nos den un número mas elevado de presos musulmanes y hebreos en este Campo de Concentración.

Es mismo 17 de julio se inician las detenciones de ciudadanos entre los que se encontraban varios hebreos, algunas programadas con antelación al Levantamiento, puesto que «tenían listas de todos los que votaron por el Frente Popular»70, organizándose para su deposito «un campamento de concentración de detenidos».

El director de Zeluán desde sus inicios fue el Capitán habilitado de la Guardia Civil Don Eusebio Martínez Izquierdo, que abandonó dicho cargo, acogiéndose a los beneficios de la Orden del 28 de Junio de 1939, siendo sustituido por el Capitán del Primer Tercio de la Legión, Don julio Cantalapiedra Rodríguez auxiliado por el Alférez del Grupo de Regulares de Alhucemas no 5 Don Pedro Guerra Leo. ${ }^{71}$

Este campo de concentración se abrió en un pueblo del Protectorado español, Zeluán con una pequeña población de 417 europeos y 42 musulmanes, instalándose dentro de su alcazaba, a escasos 30 kilómetros de Melilla, siendo un lu-

\footnotetext{
${ }^{6}$ LANUZA MEJIA, J., Así comenzó. Aportación a la historia de la sublevación militar de 1936. México, Andarivel 1972 pg 189

${ }^{69}$ AGMG. Campo de Concentración «La Alcazaba». Zeluán . Expedientes Procesales. Caja 7. Expediente 577. Santos Levy Murciano.

70 SAINZ, H., Historia de los Arraiz Madrid Sociedad General de Autores de España 1994 y AIMML Fondo Comandancia General Caja 1 sobre 1 exp. 9, Listas de personas pertenecientes a las diferentes Sociedades obreras y de compromisarios que obraban es su poder antes del 17 de julio.

${ }^{71}$ Orden General del Grupo de Fuerzas Regulares de Alhucemas nํ 5 de fecha 20 de julio de 1939. Martínez Izquierdo se encontraba a fecha 17 de julio de 1936 en situación de retirado por la edad.
} 
gar donde estaba ubicada además de la Comandancia de la Guardia Civil, la sede de los Sindicatos Agrícolas junto con otras construcciones ${ }^{72}$; tiene dicho lugar, todavía en pie, forma de cuadrilátero, midiendo los lados unos doscientos metros, siendo una construcción de finales del siglo XVII. Allí fueron a parar en un principio la mayoría de los presos políticos de la ciudad y del Protectorado, incluidos menores y mujeres, combinando durante su existencia la particularidad de funcionar a la vez de campo de concentración y de prisión compartiendo además instalaciones, al menos desde junio de 1937, con el Batallón de Trabajadores no $145^{73}$.

En contra de lo que afirma el historiador Aram Monfort ${ }^{74}$ referente a que el fenómeno concentracionario era exclusivamente masculino, he aquí en el campo de concentración de Zeluán la excepción, ya que hubo ingresadas allí algunas mujeres, al menos tenemos constancia de tres: Isabel Martínez López, Concepción Córdoba Rodríguez e Isabel Romero Quesada ${ }^{75}$, aunque el lugar habilitado para mujeres detenidas fue la cárcel de Victoria Grande.

La proximidad de Zeluán a Melilla fue uno de los factores que hicieron que se instalara allí ya que poseía una infraestructura muy completa dotada de agua corriente y electricidad, esta última proporcionada de manera altruista y gratuita por el industrial Don Cristóbal Vera Martínez que facilitó el alumbrado eléctrico para la tropa y los presos, realizando acondicionamiento e instalaciones por su cuenta y a su cargo, cediendo también gratuitamente todo el fluido eléctrico que se consumiera durante el tiempo que fuera preciso, así como el entretenimiento y todo el gasto de los aparatos Petromax y del alumbrado ${ }^{76}$.

Debido a su férrea vigilancia y ubicación existieron muy pocas posibilidades de evadirse aunque algunos lo intentaron y uno, que sepamos hasta el momento, llegó a fugarse; José Pardo García que escapó el 15 de diciembre de 1938 cuando salió a trabajar en un tejar cercano ${ }^{77}$.

Según los falangistas, este no era más que uno de los campos de concentración que se irían originando a medida que fuesen avanzando las fuerzas sublevadas, afirmación correcta ya que en España, entre 1936 y 1947 funcionaron varios campos de concentración estables y otros muchos provisionales, coordinados por el servicio de Colonias Penitenciarias Militarizadas.

72 El 30 de marzo de 1932 por una disposición del Alto Comisario, la Alcazaba de Zeluán fue cedida a la Federación de Sindicatos Agrícolas de la Región Oriental para instalar allí dos silos de cereales, almacenes de productos agrícolas, abonos químicos y una bodega cooperativa, arreglándose en esas fechas la conducción de aguas.

${ }^{73}$ AGMG. Campo de Concentración «La Alcazaba». Zeluán. Expedientes Procesales. Caja 11. Expediente 908. Juan Sánchez Pérez del Batallón de trabajadores no 145

${ }^{74}$ MONFORT, A., Barcelona 1939. El camp de concentració d Horta, Lávenç., Barcelona, 2008. 1937

${ }^{75}$ ACML Fondo Central Asuntos. Campo de Concentración de Zeluán Exp. 410 caja 211 1936-

76 Telegrama del Rif 8 agosto 1936.

${ }^{77}$ El trabajar en esos tejares fuera del campo concentración fue en cumplimiento de una orden que les llegó por telegrama Postal de fecha 12 de noviembre de 1937, sección 1ํ Justicia nํㅜ 1.310. 
Por los escritos de Carlota O Neill ${ }^{78}$ y otros testimonios, sabemos que los alojamientos de los detenidos eran en un principio unos míseros barracones y tinglados de madera construidos casi en su totalidad por ellos mismos en el patio del recinto, añadiéndose muy tempranamente tiendas de campaña ante el gran número de detenidos que fueron llegando.

El encargado de instalarlo y ubicar su seguridad fue el Comandante de Ingenieros Don Luis Sicre y Marassi, que en esos momentos estaba destinado en Melilla en la Comandancia de Ingenieros de Marruecos con el cargo de Jefe de la Delegación Oriental de la misma (Melilla) y Jefe del Detall de dicha Delegación. Fue, según su propio testimonio, uno de los primeros que se unieron a la sublevación por estar en contacto con los elementos que lo organizaron en esta Plaza, siendo nombrado en los primeros días de agosto de 1936, Presidente de la Comisión Depuradora de Detenidos (creada para depurar las responsabilidades de los estos con motivo del Movimiento y con posterioridad), por Orden del Exmo Señor Alto Comisario de España en Marruecos, además de ser nombrado Presidente de la Comisión Depuradora de Funcionarios Civiles hasta el 10 de noviembre,-que fue destinado en comisión al Cuerpo del Ejercito de Castilla-, ejerciendo a su vez como Juez eventual ${ }^{79}$.

Podemos afirmar a través del estudio de diferentes fuentes y testimonios que el Campo de Concentración de Zeluán fue muy diferente al resto. Se abrió sin regulación ni institucionalización, pero con el mismo propósito represor que los que se crearon más tarde, siendo siempre ilegal y dependiendo del desarrollo de la guerra, pero no existiendo en sus inicios prisioneros militares, soldados $u$ oficiales que fueran capturados de entre las fuerzas republicanas en actos de guerra, solamente hubo militares acusados de tenues o por no acatar las ordenes de los sublevados, ingresando a su vez, según avanzan los meses, presos comunes, además de condenados mediante juicios sumarísimos y Consejos de Guerra, funcionando como se puede comprobar como campo de concentración y cárcel, albergando también al Bon Trabajadores no 145.

El empleo de mano de obra forzosa era allí algo habitual, realizando entre otras actividades la de fabricar ladrillos o arreglar las carreteras de esa parte del Protectorado ${ }^{80}$, además de mandar diariamente a Melilla a varios presos para realizar su trabajo anterior, obligados y sin retribuciones; esto ocurrió con muchos de los trabajadores de las obras que realizara la Junta del Puerto o del mismo Telegrama del Rif81.

\footnotetext{
${ }^{78}$ O NEILL, C., Una Mujer en la guerra de España Madrid, Turner 1979

${ }^{79}$ AIMML Fondo Comandancia de Obras. Expediente del Comandante Luis Sicre Marassi, Declaración jurada de los servicios prestados en la pasada campaña del Comandante Luis Sicre y Marassi el 30 enero de 1940.

${ }^{80}$ AIMML Fondo Comandancia de Obras. Reparación carretera Tauima -Zoco Arbaa.

81 Testimonio oral de Miguel Ángel Roldán, hijo de un tipógrafo del Telegrama del Rif que a diario hizo estos viajes para que saliera a la luz la rotativa, estando ya condenado y preso en Zeluán por sus ideario político. AIMML Proyectos de obras de carretera Tavima Zoco Arba.
} 
El número exacto de presos hasta hoy en día es desconocido, las fichas encontradas nos llevan a la cifra de 134782, aunque hay que añadir otras 152 personas que aparecen en tres listas, hasta ahora inéditas rescatadas de un fondo del Archivo Central de Melilla, con los nombres de 152 melillenses que fueron liberados de allí en diferentes oleadas, añadiendo algunos más ya que sabemos por informaciones orales que algunos expedientes fueron destruidos años después, para intentar borrar su paso por ese Campo de Concentración ${ }^{8} .^{3}$

Mucho antes del decreto 281 de 11 marzo 1937, en Zeluán ya se clasificaba a los detenidos y los reubicaban según su condición y empleo, esto no quita que en años posteriores existieran allí mismo militares que no se sumaron al Alzamiento, como el Sargento Robles ${ }^{84}$ que tendría que haber ingresado en alguna de las cárceles militares existentes en la ciudad.

Eran todos depurados de una forma u otra; sabemos que alguno fue asesinado allí y enterrados en un campito cercano ${ }^{85}$, y los demás sufrieron una represión brutal siendo maltratados físicamente, incautando sus bienes, perdiendo sus empleos e inhabilitados además de ser condenados al ostracismo social.

A partir del 18 de noviembre de 1936, los civiles que abandonaban dicho Campo debían satisfacer el importe de su estancia siendo estas abonadas en la Jefatura de las Fuerzas Militares de Marruecos, sección Justicia, inaugurando dicha orden el hebreo Ramón Bensusan Benhamú ${ }^{86}$.

Los hebreos no tuvieron opción de realizar allí ninguna de sus prácticas y ritos religiosos preceptivos asistiendo ineludiblemente a las ceremonias religiosas cristianas, no ocurriendo lo mismo con los musulmanes a los que se les respetaba sus creencias.

Por dicho Decreto Franco creó la Inspección de los Campos de Concentración de Prisioneros que dio definición a los campos de concentración existentes, incluido el de Zeluán. La regulación de este sistema de campos fue progresiva a la del aparato legal y jurídico establecido para depurar y castigar las actuaciones individuales y colectivas durante la II República, creándose a la vez las Comisiones de Clasificación.

A la vuelta del frente muchos de los soldados musulmanes describían los sufrimientos pasados, siendo detenidos por dar informaciones contrarias al Movimiento Nacional ${ }^{87}$; y en muchas ocasiones, los hubo que cansados de una guerra

\footnotetext{
82 AGMG. Campo de Concentración «La Alcazaba». Zeluán. Expedientes Procesales.

${ }^{83}$ Testimonio de Santiago López que tiene referencia de que su abuelo pasó por Zeluán desapareciendo su expediente por mediación de su padre que trabajó en Comandancia General años después.

${ }^{84}$ ACML, Fondo repatriaciones Exp. 268

85 Testimonio oral de A. Zapata.

${ }^{86}$ AGMG. Campo de Concentración «La Alcazaba». Zeluán. Expedientes Procesales. Caja 2. Expediente no 123 Ramón Bensusan Benhamú.

${ }^{87}$ AIMML Expedientes de Regulares Indígenas.
} 
que no era la suya, de sufrir o de haber cogido buenos botines, abandonan el ejercito para trasladarse a Marruecos, siempre sin autorización, siendo acusados de deserción como Hamed Bern Abderraman Ayero oㅜ 5747, Mohammed Ben Haddu, Amar Ben Al-Lal Ben Tahar no 5970, Al-Lal Ben Mohamad no 5017 o Mohamed Ben Abdelá no 10.622, siendo a su captura ingresados en este Campo de Concentración de Zeluán y expulsados del ejercito ${ }^{88}$.

Otros, como Ben Si Mohan Al-Lal, fueron llevados a Zeluán por intentar simplemente embarcar en Melilla para marchar a la península mezclado en una expedición de Fuerzas Regulares. Y también los hubo acusados, como hebreos y cristianos, de sedición por el supuesto delito de injurias al Jefe del Estado como Bachir Ben Chaib que fue ingresado el 20 de noviembre de 1937 en la cárcel de ViIla Sanjurjo y trasladado posteriormente a Zeluán o Mohamed Ben Tieb Ben Tieb que fue recluido en dicho Campo y juzgado en la causa 978/193789.

Tras el termino de la Guerra Civil siguieron llegando presos a dicho Campo de Concentración como el hebreo Ruben Bitan Aserraf que ingresó el 9 de septiembre de 1939 o Jesús Abrahan Derhi filiado con el no 1334, ingresado el 18 de octubre de ese mismo año.

Algunos hebreos tras meses de reclusión fueron conducidos al Puente Internacional del Muluya -frontera con el Protectorado francés- para su expulsión de la zona, en virtud de orden del General de la Circunscripción Oriental como Sadia Bitan Pinto, Isaac Illous Benhamud o Abraham Cohen Cohen, por considerarles extranjeros.

Otros tras ser condenados y pasar por Zeluán son trasladados a Ceuta para ser recluidos en establecimientos penitenciarios como el caso de Samuel Bensusan Pacleum, Moisés Benzaquen Chocrón o el profesor de hebreo Alberto Moreno.

El 16 de septiembre de 1938 entran treinta detenidos a dicho campo, por haberlo ordenado el Delegado del Orden Público, siete de ellos hebreos; 90 y sabemos que entre los hebreos que pasaron por Zeluán solo dos fueron ingresados como presos comunes, Elías Chocron Chocron y Hananias Bensasi Benoliel; igualmente tenemos constancia de la ejecución tras juicio de Salomón Corcia Corcia, realizado en el zoco de Der Kebdani tras pasar por Zeluán, mientras que otros dos, Naftali Chocron Chocron y Isaac Mafhoda Benguigui eran sacados de allí y conducidos a la lejana penitenciaria de Uad-Lau para cumplir su condena.

Muchos fueron acusados, entre otras cosas, de ocultación de víveres en su establecimiento comercial, siendo en escasas ocasiones absueltos como Salomón Levy Chocron.

\footnotetext{
88 Ídem, Fondo de Regulares indígenas № 5

${ }^{89}$ AGMG. Campo de Concentración «La Alcazaba». Zeluán . Expedientes Procesales Caja 12. Expediente 973 Santos Tejera Acero.

${ }^{90}$ AGMG. Campo de Concentración «La Alcazaba». Zeluán. Expedientes Procesales. Caja 2. Expediente 125. Moisés Benzaquen Chocrón
} 
Según Lanuza Mejia también ingresaron en Zeluán los acaudalados hermanos Salama,: "Allí se encontraban los hermanos Salama, ricos comerciantes judíos, ambos nacidos en Melilla, a los que metieron enseguida en el campo de concentración de Zeluán, pensando, sin duda, en sacarles toda su fortuna, lo que así hicieron....».

Zeluán fue desalojado de presos y detenidos gubernativos entre finales de 1939 y primeros de 1940. El 12 de diciembre de 1939, 150 condenados con penas que oscilaban entre los dos años y cuatro meses a los 30 años fueron conducidos desde el Campo de Zeluán a la Isla de Alhucemas con su manta, jergón, plato y cuchara siendo entregados al Comandante Militar de la misma por los vigilantes de prisiones Don José Bazaga Cuevas, Don Ildefonso Reguero García y Don Félix Aguilar Fresneda que les acompañaban y portaban la documentación penal de los mismos junto con los efectos de oficina, metálico, víveres, medicamentos, menaje, etc. necesarios para su nueva ubicación.

\section{CONCLUSIONES}

Tras este trabajo de investigación, ampliable en todo caso, si surgen nuevos datos, se puede afirmar que la Melilla anterior al 17 de julio no era la ciudad franquista que se nos presentó durante cuatro décadas, sino republicana y democrática, triunfando holgadamente el Frente Popular y donde participaron activamente, tanto sindicatos como partidos, en su evolución republicana y democrática. Esta nueva situación trajo a la ciudad multitud de conflictos entre patronos, obreros y militares que se cobrarían fatalmente tras el 17 de julio.

Simultáneamente al 17 de julio afloran las primeras muestras de la infraestructura represiva de lo que más adelante será el Nuevo Estado, donde se aprecia claramente la violencia política y la represión ejercidas a través de asesinatos, juicios sumadísimos, incautación de bienes, depuraciones, etc., sobre gran parte de la población que pensaron que apoyo o colaboró con el Frente Popular, población que incluía a hebreos y musulmanes.

La izquierda melillense, como se puede comprobar, por el resultado de la sublevación, no estuvo preparada ni armada para defender el orden republicano siendo Melilla la primera ciudad que queda en la retaguardia sufriendo desde el primer día una represión que se continuó en el tiempo.

El principal objetivo del Levantamiento fue la eliminación física de sus oponentes y la disuasión mediante esta violencia política y la represión de toda posible oposición, institucionalizándose desde el primer día, como se demuestra en los archivos de los cementerios hebreo, cristiano y civil, una violencia selectiva que llevó por lo menos trescientas trece personas al cementerio entre los que había dieciséis hebreos y seis musulmanes además de ingresar más de un millar y medio en el campo de concentración de Zeluán. 
Los hebreos fueron represaliados, en su mayoría, por sus codiciadas riquezas, sus ideas y activa participación política con la izquierda melillense junto con su confesión religiosa y los musulmanes represaliados a través del hambre y la miseria que llevó al agro marroquí a vivir en la indigencia controlada por las nuevas autoridades, llevando a algunos a manifestarse en contra del Movimiento Nacional; a su vez la Comisión de Incautación de bienes de Melilla les incoa expedientes sancionadores siendo castigados por abandonar sin permiso una guerra que no era la suya, yendo todos a parar al Campo de Concentración de Zeluán.

La preparación y organización de este campo de concentración de una manera tan rápida demuestra su anterior preparación y planificación, siendo el primero de España y Europa, ya que, en la madrugada del 18 de julio y en pocas horas comienzan a ingresar ciudadanos residentes en la ciudad de Melilla y del Protectorado, estando comprendidos entre ellos al menos 58 hebreos y 14 musulmanes en diferentes etapas y por muy diferentes causas, siendo el miedo y el hambre las armas utilizadas por los sublevados para doblegarles, estando en todo momento vigilados y sometidos en todos los ámbitos.

La comunidad hebrea estaba antes del 17 de julio integrada plenamente, españolizada y sin ningún problema, contando con un barrio hebreo y dos cementerios, siendo en todo momento coherente, dinámica y con miembros de un gran nivel cultural. En 1945 se les devolverá el Colegio Hebreo, siendo en la actualidad el 1,6 por ciento de la población sumando un total de 1.100 personas colaborando activamente en la vida política, estando varios de sus miembros integrados dentro del actual Ayuntamiento.

En cuanto a la comunidad la musulmana se fue instalando en la ciudad de forma irregular, (en su gran mayoría los regulares y sus familias), nacionalizándose muchos años después, pues su religión les aconsejaba inscribirse fuera de la ciudad. Ha crecido de forma continua y rápida en las últimas décadas por la inmigración, la reagrupación familiar y su alta tasa de natalidad, hasta sumar 37.763 fieles en una población de 73.382 habitantes, estando integrados totalmente en la vida ciudadana, trabajando como funcionarios, comerciantes, obreros...; sumando en la actualidad más del cincuenta por ciento de la población Melilla, que es la primera ciudad española que ha superado, desde la reconquista, el $50 \%$ de población musulmana, caso único en Europa, por su enclave geográfico junto a Marruecos.

Esta comunidad cuenta con algunos de sus miembros en el actual consistorio, además de ser otro, recientemente, nombrado Delegado del Gobierno, Abdelmalik El Barkani. Son en la actualidad los musulmanes y hebreos melillenses, españoles de pleno derecho formando junto a las comunidades cristiana e hindú una ciudad multicultural democrática y plena. 


\section{ANEXO \\ RELACIÓN CRONOLOGICA DE HEBREOS FALLECIDOS EN MELILLA}

\section{DURANTE LA GUERRA CIVIL}

1. †19-07-1936 Moisés Chocron Benamú. Melillense. Militante socialista.

2. †19-07-1936 Fortunato (Mesod) Mahfoda Serfaty. Melillense. Militante de PSU

3. †19-07-1936 David Bitan. Argelino. Militante de Izquierda Republicana.

4. †27-07-1936, Hombre sin identificar. Identificado tras esta investigación como Jaime Cohen.

5. †28-07-1936, Antonio Gómez López, inscrito en el registro del cementerio cristiano. En su inscripción del registro civil practicada por el Capitán Juez Gonzalo de León aparece como hebreo. Presidente UGT.

6. †27-07-1936, Sadia Cohen Cohen. Militante de PSU.

8. $\nmid 28-07-1936$, Simon Ruas Serfaty. Militante del PSOE.

9. †13-08-1936, Jacob Chocrón Morely fusilado en Rostrogordo. Militante PSU.

10. $\uparrow 14-08-1936$, Abraham Benarroch Benarroch fusilado en Rostrogordo. Militante PSOE

11. †25-08-1936, Alberto (E) Benaim Benaim fusilado en Rostrogordo. Masón y militante IR

12. †22-09-1936, Maimón Levy Levy, falleció en el Batallón de Cazadores ํㅡㄴ 3 de una paliza.

13. $\nmid 22-05-1937$, Mauricio (Moises) Benhayon Benaim ejecutado en Rostrogordo

14. †03-07-1937, Moisés Botebol Benaim (Benhamou) fallecido en Rostrogordo a consecuencia de heridas de arma de fuego.

15. †09-05-1938, Judas Millara Semani, falleció en el Hospital de la Cruz Roja a consecuencia de herida recibida.

16. †15-02-1940, Rubén Bitan Asraraf, fallecido en la Prisión del partido de tuberculosis pulmonar., pasando antes por Zeluán y Salomón García García fusilado en Zoco Der Kedani en noviembre de 1936. 


\section{MUSULMANES DETENIDOS EN ZELUÁN}

1. Haddu Ben Mimun Ben Hayat, soldado desertor.

2. Mohamed Ben Abdela soldado desertor.

3. Mohamed Ben Abderraman № 5747 Regulares № 5-soldado desertor.

4. Amar Ben Al-Al soldado desertor.

5. Mohamed Ben Haddu soldado desertor.

6. Abselam Ben Mimun soldado desertor.

7. Mohamed Ben Mizian Ben Amar soldado desertor.

8. Hamido Ben Mohamed soldado desertor.

9. Mohamed Ben Mohamed soldado desertor.

10. Hamido Ben Mohamed soldado desertor.

11. Mohamed Ben Mohamed soldado desertor.

12. Mohemed Ben Si Mohamed Al-Lal intento de pasar a España.

13. Mohamed Ben Tieb Ben Tieb, causa 978/1977 por injurias al Jefe del Estado.

14. El Hadi Buxta Ben Moh ํo 1846 soldado Regulares $n^{\circ} 5$ por propaganda contraria al Movimiento Nacional.

\section{HEBREOS DETENIDOS EN ZELUÁN CON SU № DE FILIACIÓN}

1. № 1334 Jesús Abrahan Derhi, fontanero con residencia en Tánger.

2. № 862 Jaime Barcesat Benhuman, vendedor ambulante de Uazan, Protectorado francés, detenido el 14-5-38 hasta 22-9-38.

3. Moises Behamu Aserraf

4. Moises Benhamu Benhavides, cartero, condenado a 20 años.

5. Sadia Benofe Siboni.

6. Efraim Benaim Benzaquem.

7. № 88 Isaac Benaim Benaim, escribiente Ingresado el 23-8-36 al 14-5-38 por movilizado.

8. № 1098 Efrain Benain Bendayam, jornalero de Beni-Tusin -Marruecos español-ingresa el 16-9-1938 al 20-9-38 llevado al Hacho (Ceuta) a disposición del Alto Comisario. 
9. Mimun Benamu Benamu

10. № 87 Salomon Benarroch Hadida de Melilla, agente comercial Ingresó 242-37 al 16-8-37 conducido a Ceuta para ser destinado a establecimiento penal; condenado por procedimiento sumarísimo no 233/1937 a la pena máxima, 30 años, acusado de injurias al Movimiento.

11. Isaac Benhamú Elvas, casado, comerciante de Beni Sidel, -Marruecos español-, detenido el 25 abril de 1937 procesado por auxilio a la rebelión -sumario 239/1937- condenado a 12 años y un día de reclusión temporal, trasladado el 16 agosto 1937 a Ceuta

12. № 1099 Moisés Benhamud Asarraf, casado con dos hijos natural de Tarfesit -Marruecos español- que residía en Melilla en el Monte de María Cristina $n^{\circ}$ 17, jornalero, detenido gubernativo ingresado en Zeluán el 16 de septiembre de 1938.

13. Mimon Benhamu Benhamud, casado, natural de Melilla, jornalero, detenido gubernativo del 16-9-1938; trasladado el día 20 a la Fortaleza Militar del Hacho para quedar en dicho establecimiento a disposición del Alto Comisario

14. Elias Benhamun Benhamun, en septiembre de 1936 estaba ingresado en Zeluán condenado a la pena de reclusión perpetua, 30 años y trasladado en diciembre de 1939 a la isla de Alhucemas.

15. № 92 Isaac Benitah Amselem, casado, natural de Larache y vecino de ViIla Sanjurjo,interprete, ingresado el 20 de octubre de 1936 en calidad de preso, procedente de la Isla de Alhucemas y el 2 de julio de 1938 conducido al Hacho por orden del General de la Circunscripción.

16. № 94 Hananias Bensasi Benoliel, casado, natural de Tetuán y vecino de Melilla, empleado, ingresado el 24 de mayo de 1937 para cumplir un arresto de dos meses y un día por un hurto que cometió en junio de 1935. Fue puesto en libertad el 29 de julio de 1937.

17. № 95 Ramón Bensusan Benhamu, natural de Duddu -Marruecos francésy vecino de Taurit, comerciante y casado, ingresado el 20 octubre de 1937 procedente de la isla de Alhucemas y puesto en libertad el 22 de noviembre de ese mismo año; reingresa el 10-1-1938 como detenido gubernativo y llevado a la prisión de partido de Melilla el 3 de noviembre de 1938.

18. № 96 Samuel Bensusan Pacleum, vecino de Melilla, soltero, empleado de Banca, realizando el servicio militar en el Bon de Cazadores $\mathrm{n}^{\circ} 3$, ingresado el 10 octubre de 1936, juzgado por la causa 306/1936 por delito de sedición, condenado a 20 años de reclusión temporal trasladado el 16 de 
agosto de 1937 a Ceuta para ser destinado a establecimiento penitenciario.

19. Farahon Benzaquem.

20. № 1101, Moisés Benzaquem Chocron natural del campo de Alhucemas y vecino de Melilla, casado, jornalero que ingresa el 19-9-1938 como detenido gubernativo hasta el 20-9-1038 que es conducido a la Fortaleza militar del Hacho en Ceuta a disposición del Alto Comisario.

21. № 1307 Rubén Bitan Aserraf, natural y vecino de Melilla, soltero, vendedor ambulante, ingresado el 9-9-1939 hasta el 9-12-1939 que es conducido a la cárcel de Melilla.

22. David Bittan Bentolila, natural y vecino de Melilla, casado con dos hijos, interprete, detenido gubernativo ingresado el 31-1-1938 hasta el 3-2-1939 que es conducido a la prisión de Melilla.

23. № 106 Sadia Bittan Pinto, natural de Oran y vecino de Melilla, soltero, limpiabotas, ingresa como detenido gubernativo el 12-11-1936 hasta el 2-21937 que es liberado por movilizado y el 11-2-1937 reingresa de nuevo como detenido gubernativo siendo conducido el 20-2-1938 al Muluya para su expulsión de la zona.

24. № 864 Sadia Bonafe Siboni, natural y vecino de Melilla, casado con tres hijos, vendedor ambulante. Ingresa el 14-5-1938 al 29-6-1938 que es puesto en libertad.

25. Alfredo Charvit Benhamu, expulsado de la zona española por el puente internacional del Muluya el 14-5-1937 procedente del Campo de Concentración de Zeluán.

26. № 195 Alberto Chocron Bittan natural y vecino de Melilla, soltero, tenedor de libros, ingresa como preso el 17-11-1936 hasta el 16-2-1938 que pasa a detenido gubernativo y es puesto en libertad el 14-5-1938.

27. № 196 Yamin Chocron Bittan, natural y vecino de Melilla, soltero, cobrador. Ingresa como preso el 6-8-1936 hasta el 16-2-1938 que pasa a detenido gubernativo siendo puesto en libertad el 16-5-1938.

28. № 1110 Marcos Chocron Chocron, natural del campo de Alhucemas y vecino de Melilla, casado con un hijo jornalero que ingresa como detenido gubernativo el 16-9-1938 hasta el 20-9-1938 que es conducido a la Fortaleza militar del Hacho para quedar en dicho establecimiento a disposición del Alto Comisario.

29. № 1044 Naftali Chocron Chocron natural de Beni Sidel, vecino de Melilla casado con cuatro hijos, estibador, el más anciano de todos, en 1938 tenía 70 años. Fue detenido y llevado a Zeluán como preso el 9-9-1938 y 
puesto en libertad el 4-3-1939, reingresando el 9-3-1939 saliendo su sentencia del sumario 429/1938 condenado a 12 años y un día de reclusión temporal por auxilio a la rebelión conducido a la lejana penitenciaria de Uad-Lau para cumplir la condena

30. № 1111 Sadia Chocron Chocron, natural de Sonoya y vecino de Melilla, casado, jornalero, detenido gubernativo del 16-9-1938 hasta el 20-9-1938 que fue conducido a la fortaleza militar del Hacho (Ceuta).

31. № 197 Elías Chocron Chocron, natural de Taza (Marruecos francés) y vecino de Melilla, casado con dos hijos, jornalero, ingresado el 9-8-1936 por robo y estafa con la causa 340/1936 siendo puesto en libertad el 30-101936 por haber cumplido los diez días de arresto

32. № 869 Isaac Chocron Elos, natural de Taza -Marruecos francés-, casado con dos hijos, jornalero que ingresó en Zeluán el 18-5-1938 al 12-9-1938 que salió en libertad.

33. № 1112 David Chocron Morely, natural de Taza -Marruecos francés- y vecino de Melilla, jornalero que ingresó el 16-9-1938 al 20-9-1938 que fue conducido a la fortaleza del Hacho para quedar en dicho establecimiento a disposición del Alto Comisario.

34. № 263 Sansaya Chocron Morely, natural de Taza -Marruecos francés-y vecino de Melilla, jornalero que ingresó el 9-9-1938 hasta el 3-2-1939 conducido a la prisión de partido de Melilla.

35. № 168 Aaron Cohen Cohen 1ํ, natural de Melilla, soltero, dependiente que ingresó en Zeluán el 31 de julio de 1936.

36. № 168 Aaron Cohen Cohen (2)

37. № 169 Aaron Cohen Cohen (3ํ)- natural de Taurit -Marruecos francés-, vecino de Melilla, casado con dos hijos, cobrador, procedente de la cárcel de Nador ingresa como preso el 4-9-1936 hasta el 16-2-1938 que pasa a detenido gubernativo hasta el 3-2-1939 que es trasladado a la prisión de partido de Melilla hasta el 5-5-1939 que es puesto en libertad. Fue acusado de pertenecer al Socorro Rojo Internacional en causa 1105/1936.

38. Abraham Cohen Cohen, expulsado de la zona española por el puente internacional del Muluya el 14 de mayo de 1937 procedente del Campo de Concentración de Zeluán.

39. № 170 Salvador Cohen Cohen, natural y vecino de Tetuán, soltero, legionario en Tauima que ingresó en Zeluán el 4-5-1937 acusado de mutilación voluntaria para no ir al frente, -aunque realmente lo que ocurrió es que en enero de 1937 intentó suicidarse-, acusación que fue desestimada y saliendo en libertad el 20-5-1938 estando ya de baja la Legión. 
40. № 174 Moises Corcia Benaim, natural de Melilla, soltero de profesión empleado, ingresado el día 1-9-1936 por la causa 995/1936 y juzgado con 23 personas más el 24-2-1937 condenado a 20 años y conducido el 16-81937 a Ceuta para ser destinado a establecimiento penal.

41. Salomón Corcia Corcia, que residía en la yemaa de Tazaguin de la fracción de Izaomen de la kábila de Beni Said, sometido a juicio sumarísimo 712/1936 el 6-11-1936 por haber hecho manifestaciones tendenciosas contra al Movimiento Nacional y ocultación de víveres en su establecimiento comercial, condenado a pena de muerte y ejecutado en el zoco de Dar Kebdani.

42. № 354 Isaac Illous Benhamu, natural de Fez, detenido gubernativo del 158-1936 a 20-2-38 que es conducido al Muluya para su expulsión de la zona.

43. Jacob Levy Bendayan, estudiante, condenado a 30 años.

44. Judah Levy Bendahan, condenado por la causa 1005/1936 el 14-3-1939 junto con 15 personas más procedimiento que siguió el coronel ingenieros Juez Don Andrés Fernández Mulero contra los pertenecientes al Socorro Rojo Internacional; acusado de pertenecer a izquierda republicana y a las juventudes de esta, Condenado a reclusión perpetúa.

45. León Levy Bendahan, soltero, mecánico de radio, ingresó en Zeluán el 2211-1936 Fue detenido el 16-11-1936 en su casa por falangistas. El 20-11937 se dispone quede detenido gubernativo siendo clasificado el 23 de abril por la Junta Depuradora en el $3^{\circ}$ Grupo, es decir que debía quedar detenido hasta que volviese la normalidad. Acusado, por los informes facilitados por Falange Española, de pertenecer a izquierda republicana y al Socorro Rojo Internacional. Fue condenado a la pena de reclusión temporal de 20 años por auxilio a la rebelión.

46. Salomon Levy Chocron, detenido el 11-9-1936 e ingresado el día 13 de octubre después de pasar por la cárcel pública de Nador y Fuerte Camellos. Fue juzgado por sumarísimo 712/1936 el 6-11-1936 por ocultación de víveres en su establecimiento comercial, siendo sobreseída su causa y puesto en libertad el 16 de diciembre.

47. Fortunato Levy Levy, detenido por un oficial de Regulares el 18-7-1936 zapatero y limpiabotas, casado con tres hijos, fue sobreseída su causa y puesto en libertad el 4-4-1937.

48. № 387 Santos Levy Murciano, natural y vecino de Melilla, casado con cuatro hijos, camarero, ingresado el 19 de julio de 1936, proveniente de la cárcel de Nador; detenido e ingresado por la Mejaznia en concepto de preso hasta el 16-2-1938 que fue clasificado por la Junta Depuradora de $3^{\circ}$ grupo, es decir que debía estar detenido como gubernativo hasta la vuelta a la 
normalidad hasta el 16 de mayo de ese año que es puesto en libertad con 123 personas más de las cuales tres eran de religión hebrea. Acusado de votar al Frente Popular y ser amigo del médico Ramos.

49. № 388 Yudah Levy Ruas, natural de Beni-Tuzin y vecino de Nador, casado comerciante. Fue detenido por Falange el 22-8-1936, enjuiciado en la causa 1062/1936 instruida por actividades masónicas. Clasificado el 13-31938 de $3^{\circ}$ grupo, es decir que debía estar detenido como gubernativo hasta la vuelta a la normalidad, fue puesto en libertad el 24-6-1939.

50. № 428 Isaac Mafhoda Benguigui, natural de Beni-Tuzin y vecino de MeliIla, casado con siete hijos, representante, ingresó el 3-8-1936 hasta el 7-91939 que es conducido a la prisión indígena de Uad-Lau. Condenado a 20 años de reclusión temporal causa 297/1938 por auxilio a la rebelión junto a dos personas más el 29-8-1938.

51. Jose Mafhoda Serfati, oficinista condenado a 20 años.

52. Jacob Murciano Genafo, detenido gubernativo puesto en libertad el 24 diciembre 1936.

53. Merida Murciano Murciano, liberado 16 de mayo de 1938 junto a 123 personas más de las cuales, tres eran de religión hebrea.

54. Moises Obadia Morely, ingresado en Zeluán el 16-5-1938, causa 243/1938 sobreseída y puesto en libertad el 7 de septiembre de ese año.

55. Sadia Rhanz Levy, detenido gubernativo puesto en libertad el 24 diciembre 1936.

56. Denas Ruas Sultan.

57. Jacobo Salama.

58. Sr. Salama (hermano pequeño). 


\title{
TELEGRAMA OFICIAL PARA Zeduan
}

\author{
Melilla $18_{\text {de Noviembre de 193...6 CALIFICACIÓN }} 6$ C
}

\section{EL CORONEL JEFE DE LA CIRCUNSCRIPCION}

$A L$

Capitan Inspector de Prisiones Jefe Alcazaba de zeliun.

Con esta fedha digo a Capitan Jefe Guardia Civil y Orden Publicolo siguiente:

"Disponga yue por personal a sus ordenes sea trasladado desde la Alcazaba de Zeluan a esta pl za el paisano RAMON BENSUSAN BENHAMU, poniendolo en libertad, sirviendose ordenarle que en el ter. mino de 48 horas se presente en esta Jefatura (Seccion Justicia) con el fin de abonar el impor. te de las estancias causadas por el mismo en la mencionada Al cazaba, cuyo extremo lo tendra en cuenta en lo sucesivo en ordenarlo a todos cuanto individuos se pongan en libertad."

Lo digo a V. a fin de que proceda a la entre ga del mencionado individuo a los fines expuestos
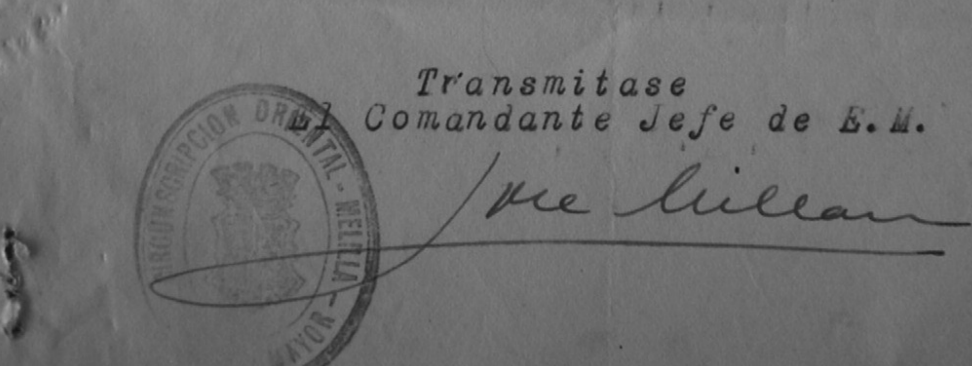

AGMG Documento donde aparece el abono por estancia en Zeluán 


\section{Elencelio de Espấa en Alricer}

\section{CUARTEL GENERALL}

\section{REGISTRO CENTRAL DE PRESOS Y DETENIDOS}

\section{Circunscripción \\ Oxastat \\ Sector}

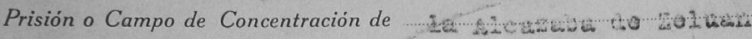

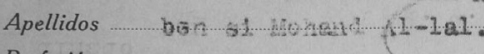

Profesión

edad

Nombre Loswned.

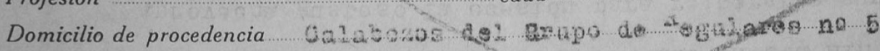

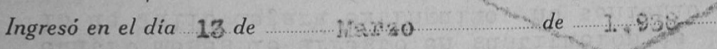

¿Está sujeto a procedimiento judicial? ........................

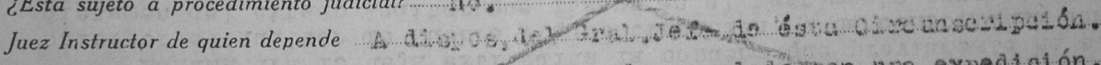

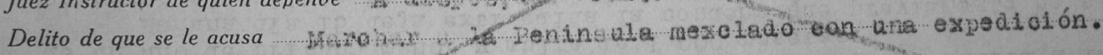
¿Es detenido Gubernativo?

Motivo de la detención _..........

Fué puesto en libertad en ........ de

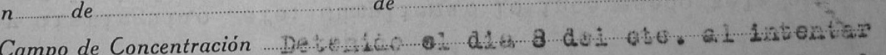

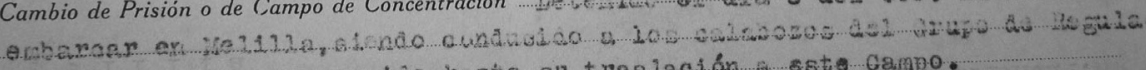

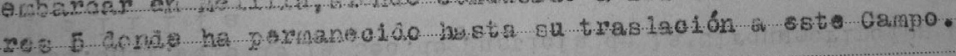

AGMG expediente del musulmán Mohamed Ben Mohan ingresado en Zeluán

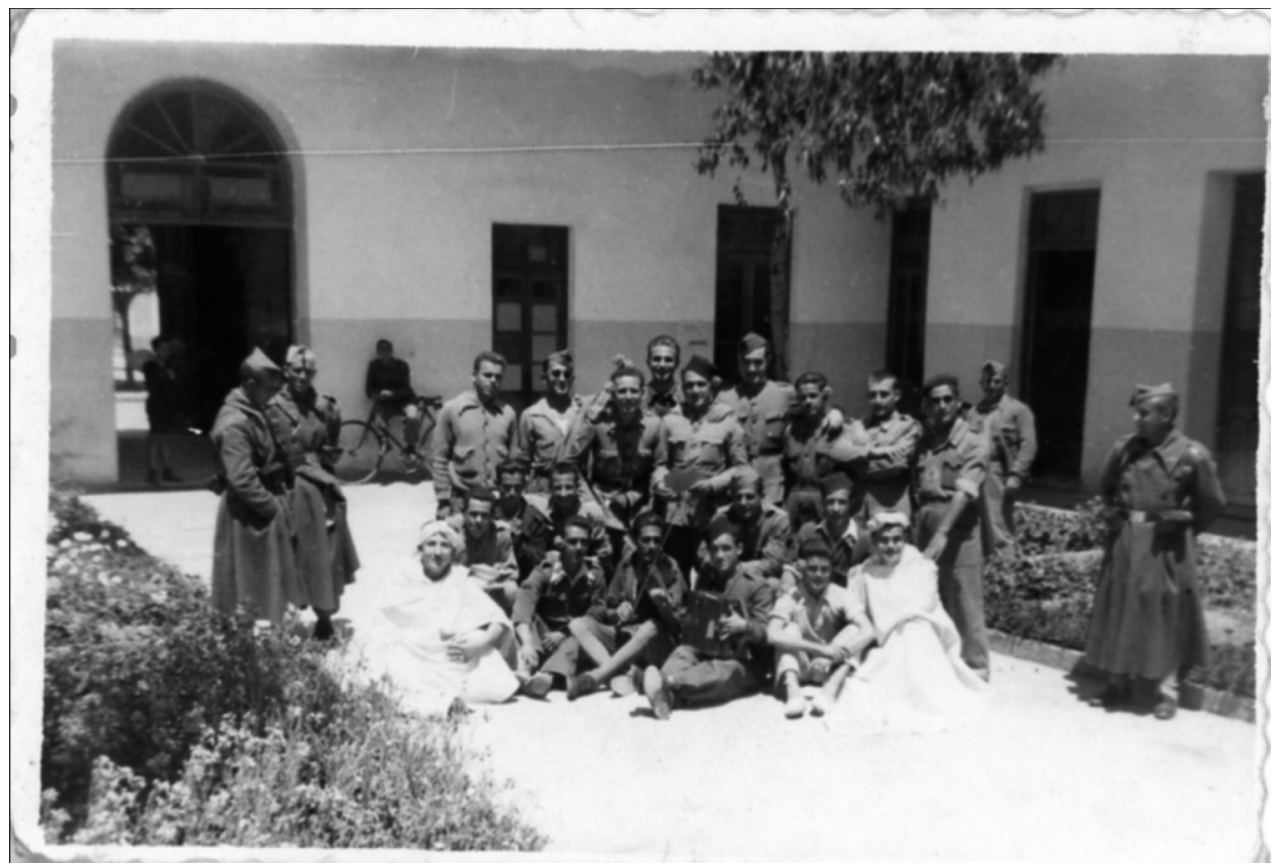

Falangistas en el Colegio Hebreo de Melilla tras la incautación 


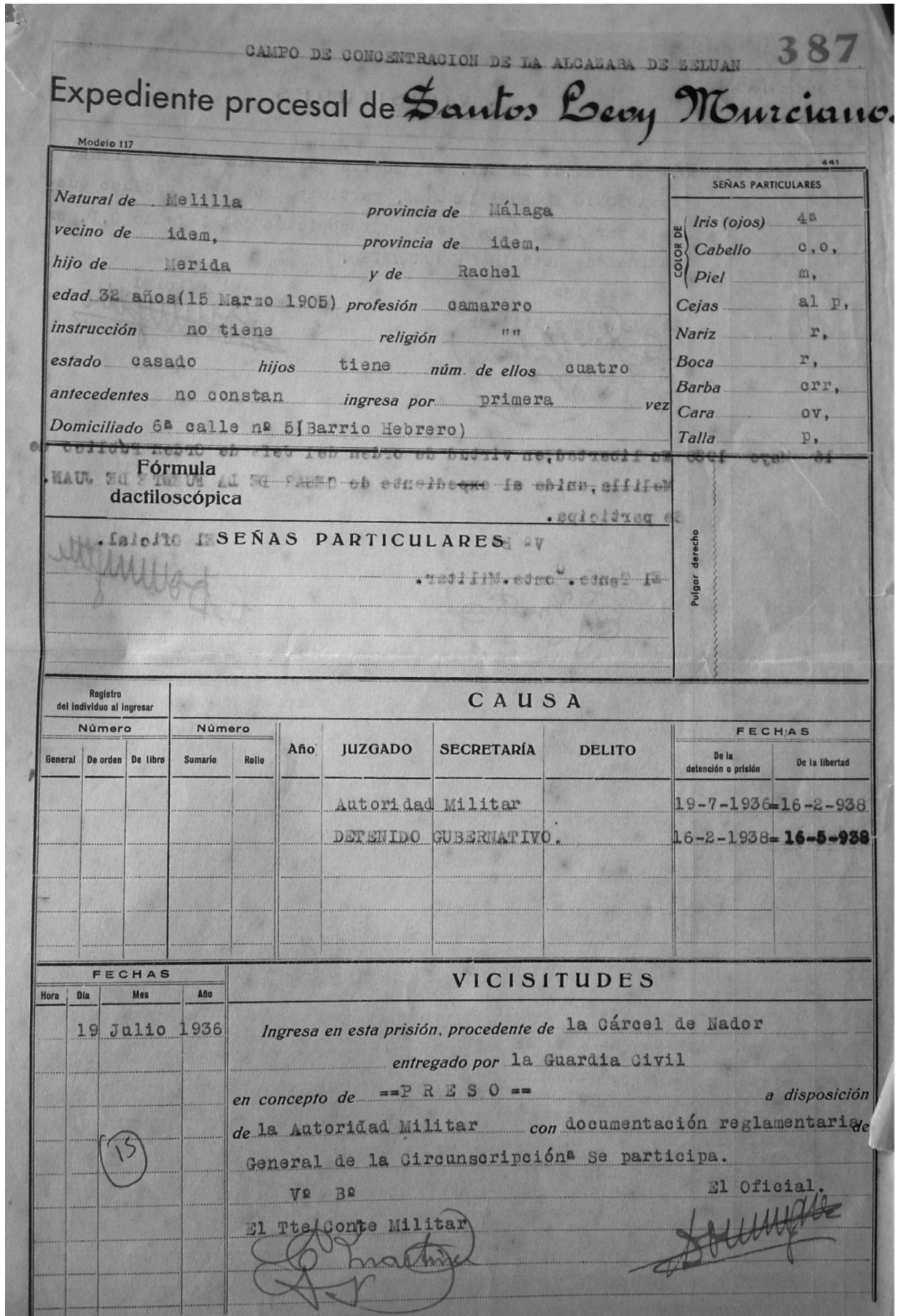

AGMG Expediente procesal donde aparece el 19 de julio como fecha de ingreso en el C.C. Zeluán 
